\title{
Psychological effects of implantable cardioverter defibrillator shocks. A review of study methods
}

\section{Gian Mauro Manzoni ${ }^{1,2 *}$, Gianluca Castelnuovo ${ }^{1,2}$, Angelo Compare ${ }^{3}$, Francesco Pagnini' ${ }^{2}$, Vidal Essebag ${ }^{4}$ and Riccardo Proietti ${ }^{5}$}

1 Psychology Research Laboratory, Istituto Auxologico Italiano IRCCS, Verbania, Italy

2 Department of Psychology, Catholic University of Milan, Milano, Italy

${ }^{3}$ Department of Psychology, University of Bergamo, Bergamo, Italy

${ }^{4}$ McGill University Health Center, Montreal, OC, Canada

${ }^{5}$ Cardiology Department, Luigi Sacco Hospital, Milano, Italy

\section{Edited by:}

Sayyed Mohsen Fatemi, Harvard

University, USA

Reviewed by:

Valentina leraci, University of Turin, Italy

Mingna Liu, Northwestern

University, USA

${ }^{*}$ Correspondence:

Gian Mauro Manzoni, Psychology

Research Laboratory, Istituto

Auxologico Italiano IRCCS, Via

Cadorna 90, 28824 Piancavallo

(Oggebbio), Verbania, Italy

e-mail:gm.manzoni@auxologico.it
Background: The implantable cardioverter defibrillator (ICD) saves lives but clinical experience suggests that it may have detrimental effects on mental health. The ICD shock has been largely blamed as the main offender but empirical evidence is not consistent, perhaps because of methodological differences across studies.

Objective: To appraise methodologies of studies that assessed the psychological effects of ICD shock and explore associations between methods and results.

Data Sources: A comprehensive search of English articles that were published between 1980 and 30 June 2013 was applied to the following electronic databases: PubMed, EMBASE, NHS HTA database, PsycINFO, Sciencedirect and CINAHL.

Review Methods: Only studies testing the effects of ICD shock on psychological and quality of life outcomes were included. Data were extracted according to a PICOS pre-defined sheet including methods and study quality indicators.

Results: Fifty-four observational studies and six randomized controlled trials met the inclusion criteria. Multiple differences in methods that were used to test the psychological effects of ICD shock were found across them. No significant association with results was observed.

Conclusions: Methodological heterogeneity of study methods is too wide and limits any quantitative attempt to account for the mixed findings. Well-built and standardized research is urgently needed.

Keywords: implantable cardioverter defibrillator, ICD shock, quality of life, anxiety, depression, review

\section{INTRODUCTION}

The implantable cardioverter defibrillator (ICD) has become the treatment of choice for both primary and secondary prevention of sudden cardiac death (SCD) due to ventricular arrhythmias (VA). Major clinical trials have consistently shown the ICD to be superior to antiarrhythmic drugs in patients at high risk (Buxton et al., 1999; Kuck et al., 2000; Connolly et al., 2000a,b; Moss et al., 2002; Bardy et al., 2005). As ICDs can avoid SCD but cannot affect the underlying cardiac substrate, the prolonged lifespan enjoyed by patients with significant heart disease is thus shifting the clinical burden to the resulting increase in heart failure events (Sears et al., 2006; Mishkin et al., 2009) and to the possibility of repeated shocks (Barnay et al., 2007). Reported rates of appropriate ICD shocks range from $60 \%$ in the 3-year secondary prevention AVID study (Anderson et al., 1999) to $20 \%$ in the 2-year primary prevention MADIT II trial (Moss et al., 2002).

As many patients who receive a shock develop some form of psychological distress in the aftermath (Sears and Kirian,
2010), the possible relation between ICD shocks and psychological distress/disorders or reduced QoL was assessed with particular attention. Investigations of such relationship were largely confined to descriptive or observational studies because of the clear impossibility to control the shock factor and thus to use randomized designs. Despite these limitations, an amount of studies attempted to test the hypothesis that ICD shocks are responsible for the occurrence of psychological distress/disorders and the reduction of QoL in ICD patients. However, findings were promptly discordant (Sears et al., 1999; Burke et al., 2003) and the supposed negative effect of ICD shock on patients' QoL and psychological health is still an object of debate (Pedersen and Van Den Broek, 2008; Pedersen et al., 2010b).

In order to examine whether such mixed findings might depend on design and methodological differences, we reviewed and critically appraised all quantitative studies that statistically assessed the effect of ICD shocks on psychological variables such as QoL, anxiety, depression, psychological stress or well-being and 
post-traumatic stress disorder (PTSD) in patients implanted with an ICD for primary and secondary prevention.

\section{METHODS \\ STUDY ELIGIBILITY CRITERIA \\ Types of studies}

Quantitative studies that statistically assessed the association between ICD shock and psychological outcomes were included. Qualitative and single-case or case-series reports were not considered. Studies were selected irrespective of designs, aims, hypotheses, time from ICD implantation and length of follow-up. Studies that explicitly assessed the causal effect of psychosocial factors on ICD shock occurrence were not considered.

\section{Types of participants}

Patients of age $\geq 18$ implanted with an ICD for primary or secondary prevention of SCD were considered. No restriction was made on patients' clinical and demographic characteristics with the exception of age. Young patients of age $<18$ were not considered.

\section{Types of intervention}

Only automatic ICD shock therapy was considered. No restriction was made on appropriateness (both appropriate and misappropriate shocks were considered), duration, electric power and the absolute or relative number of delivered shocks (isolated shocks, electric storms and shock clusters were considered).

\section{Types of outcome measures}

Only valid and reliable standardized measures of psychological and quality of life outcomes were considered. Anxiety, depression, PTSD and health-related quality of life measures were specified in advance and documented in the review protocol. However, no restriction was made on any other psychological outcomes that were measured in a valid and reliable manner.

\section{REPORT ELIGIBILITY CRITERIA}

Only English articles that were published in indexed journals were considered. Abstracts, letters, unpublished data and gray literature in general were not searched nor considered.

\section{DATA SOURCES}

A comprehensive search of English articles that were published between 1980 and 30 June 2013 was applied to the following electronic databases: PubMed, EMBASE, NHS HTA database, PsycINFO, Sciencedirect and CINAHL. Since the first ICD implantation took place in 1980 , it was unnecessary to search records predating that year. Bibliographies of included studies were screened for further references.

\section{LITERATURE SEARCH}

A two-step search strategy was used. We arbitrarily defined four time intervals (1980-1996, 1997-2003, 2004-2007, 2008-2011) and randomly assigned each of them to one of four independent reviewers who had been previously instructed about the search protocol. We first searched online databases for the following terms in article titles or abstracts: ICD, implant* ${ }^{*}$ defib*, cardiover*, (internal near defib*), (internal near cardiover*), (implant* near cardiover*), (implant* or internal), (cardiac near defib*), (implant* and defib*), (internal and defib*), (cardiac and defib $\left.^{*}\right)$. We recorded results in a reference database (EndNote $\mathrm{X} 2$, the Thomson Corporation). The second step refined the first search by filtering for the following terms: mood, quality of life, QOL, health, health-related quality of life, adjust*, psych*, anx*, depress*, stress, well-being.

\section{STUDY SELECTION}

Studies identified by the whole search strategy were assessed for inclusion through three stages. First, three independent reviewers (GMM, RP, and GC) screened titles and abstracts of papers to exclude irrelevant records. Full-texts of remaining papers were obtained and assessed against eligibility criteria by the same independent reviewers at the second stage. Any differences in opinion were resolved through discussion with a forth independent reviewer at the third stage.

\section{DATA COLLECTION}

All included studies were randomly and equally assigned to three review authors (GMM, RP, SC) who independently extracted and coded data in accordance to a refined sheet. Information was extracted on: (1) design and aim of study, (2) ICD indication (primary, secondary or both) and programming (only shock or shock and pacing); (3) demographic characteristics of participants implanted with an ICD (age and sex); (4) inclusion and exclusion criteria; (5) number of participants included in the analysis and lost to follow-up; (6) shock therapy; (7) timing of psychological assessments and length of follow-up; (8) outcome measures; (9) statistical analysis; (10) results.

\section{RISK OF BIAS ASSESSMENT}

The Cochrane data collection form for non-randomized studies and the Newcastle-Ottawa scale for assessing quality of cohort studies were used to assess risk of bias and to ascertain the validity of studies. Both templates were retrieved from the Cochrane Handbook for Systematic Reviews of Interventions, Chapter 13, Supplementary Material (retrieved at www.cochrane.org/ training/cochrane-handbook). The same three review authors (GMM, RP, and GC) who extracted data determined also the adequacy of: (1) ascertainment of shock exposure; (2) demonstration that outcomes of interest was not present before ICD implantation; (3) control for confounding; (4) assessment of outcomes (self-report or interview); (5) validity and reliability of outcome measures; (6) completeness of data set. Furthermore, the review authors appraised the method used for identifying relevant confounders and the method used for controlling relevant confounders.

\section{DATA ANALYSIS}

Wide methodological differences were promptly observed across studies during the review process. The feasibility of standardizing individual study results and combining them in a meta-analysis was thus discussed several times during the first intermediate meetings and no consensus was established before the middle of the review process when we decided not to perform any metaanalysis. As reported extensively in the results section, included studies differ in many characteristics, in particular analytical and 
operationalizing methods, and statistical combination of data from two or more similar studies in a meta-analysis may be neither necessary nor desirable (Liberati et al., 2009). Hence, the extracted data were only qualitatively analyzed and tabulated. Despite the danger of poor validity associated to quasiquantitative methods such as vote counting, we decided also to perform subgroup analyses in order to explore if significant results depend on the methodological factors we specified in advance. Publication bias or selective reporting bias were not systematically assessed because we did not specify this possibility before starting the review and, even if we observed some clues of selective reporting in a number of articles, we decided not to investigate further.

\section{RESULTS}

\section{STUDY SELECTION}

A total of 60 studies were identified for inclusion in the review (Table 1). The first-step search of electronic databases provided a huge amount of records that were then drastically reduced with the filtering for the second-step search terms. Of these records, a large part was discarded in accordance to the report eligibility criteria and because, after screening the abstracts, it appeared that these studies clearly did not assess a statistical association between ICD shock and the outcomes of interest. No further article was discarded after examining the full text of the remaining 60 records. No additional study was identified by checking the references of relevant papers, by searching for studies that have cited these papers or by contacting the principal authors of the field.

\section{CHARACTERISTICS OF INCLUDED STUDIES \\ Designs}

Study designs were coded considering only the part of study in which an association between ICD shock and outcomes of interest was assessed. According to criterion, 32 studies out of 60 were classified as cross-sectional, 27 as prospective and 1 as randomized controlled trial (RCT). Hence, prospective cohort studies that evaluated the effect of shock cross-sectionally (e.g., Mark et al., 2008) were coded as cross-sectional. Only cohort studies that assessed the effect of ICD shock on change in psychological variables and quality of life along time were considered prospective. Six of the included studies are randomized controlled trials (Namerow et al., 1999; Irvine et al., 2002; Schron et al., 2002; Strickberger et al., 2003; Wathen et al., 2004; Mark et al., 2008) but three out of them were classified as cross-sectional (Namerow et al., 1999; Strickberger et al., 2003; Mark et al., 2008) and two as prospective (Irvine et al., 2002; Schron et al., 2002) because assessment of the shock effect was a sub-analysis performed only on patients randomized to the ICD condition. Only the PainFREE Rx II trial (Wathen et al., 2004) was coded as RCT because the ICD shock was partially manipulated. In fact, patients with ICDs were randomized into two treatment conditions that differed only for the delivering of shock therapy or anti-tachycardia pacing.

\section{Participants with ICDs}

The included studies vary a lot with respect to sample sizes. The study with the smaller sample involved 15 ICD patients and has a prospective design (Dougherty, 1995), while the study with the larger sample included 816 ICD patients and was coded as crosssectional although it is an RCT comparing amiodarone vs. ICD in heart failure patients (Mark et al., 2008). Considering only patients with an ICD whose data were included in statistical analyses and contributed to results, the whole number of participants considered in this review is 10558 . The average of the mean ages of patients across the included studies is 61.2 with a standard deviation (SD) of 3.6 (range: 53-69.1), while the average of the relative SDs is 12.1 (range: 6.3-16). Patients included in the studies were mainly males. Percentages of females varied from $0 \%$ (Keren et al., 1991; Burgess et al., 1997; Goodman and Hess, 1999) to $81 \%$ (Pedersen et al., 2008b) with a mean of only 20\% (SD 10.9\%).

\section{ICD indication}

As expected, studies that involved only patients with a secondary ICD indication are more frequent than studies that recruited only patients with a primary ICD indication (22 vs. 10$)$. Samples were heterogeneous (both patients with a primary indication and patients with a secondary prevention were recruited) in 22 studies, while in 6 papers no information about ICD indication was reported and relative studies were thus not classified (see Table 1 for details).

\section{ICD Shock therapy}

Twenty-seven studies operationalized number of ICD shocks in a dichotomized variable with patients who received 1 or more shocks classified in one category and patients who did not receive any shock assigned to the other one. Across 22 out of 27 studies that operationalized ICD shocks in this manner (no shock vs. $\geq 1$ shocks), $38.5 \%$ of patients received at least 1 shock on average. The smallest percentage of patients who received 1 or more shocks (4.2\%) was found in the study of Van Den Broek et al. (2009), while the higher (64\%) was found in the study of Crossmann et al. (2007), followed by Jacq et al. (2009) and Bilge et al. (2006) with $61.5 \%$ shocked patients. In five of the articles describing the studies that we classified in this category (no shock vs. $\geq 1$ shocks), data about percentage of patients who received 1 or more shock from their ICD were lacking (Keren et al., 1991; Kamphuis et al., 2002; Wathen et al., 2004; Cuculi et al., 2006; Piotrowicz et al., 2007). Indeed, some articles reported only the number, the mean or the median of ICD shocks delivered during the study period. Furthermore, we found that two articles classified in this category (no shock vs. $\geq 1$ shocks) described two studies whose aims and hypotheses were different but shared the same sample (Pedersen et al., 2004, 2005). Two studies operationalized number of ICD shocks in a dichotomized variable with patients who received 5 or more shocks classified in one category and patients who received between 0 and 4 shocks assigned to the other one. In Luderitz et al.'s study (1993), 57.9\% of ICD patients received 5 or more shocks during a 12-month follow-up, while in the Von Känel et al.'s study (2011), 8.4\% received 5 or more shocks before baseline assessment $(24.4 \pm 20.7$ months post ICD-implantation $)$ and $19.3 \%$ received 5 or more shocks between the baseline and the end of follow-up ( $65.5 \pm 27.4$ months post ICD-implantation). Nine studies categorized ICD shocks in multiple groups and eight different categorizations were used. Three studies out of them created an extreme group of patients who had received ten or 


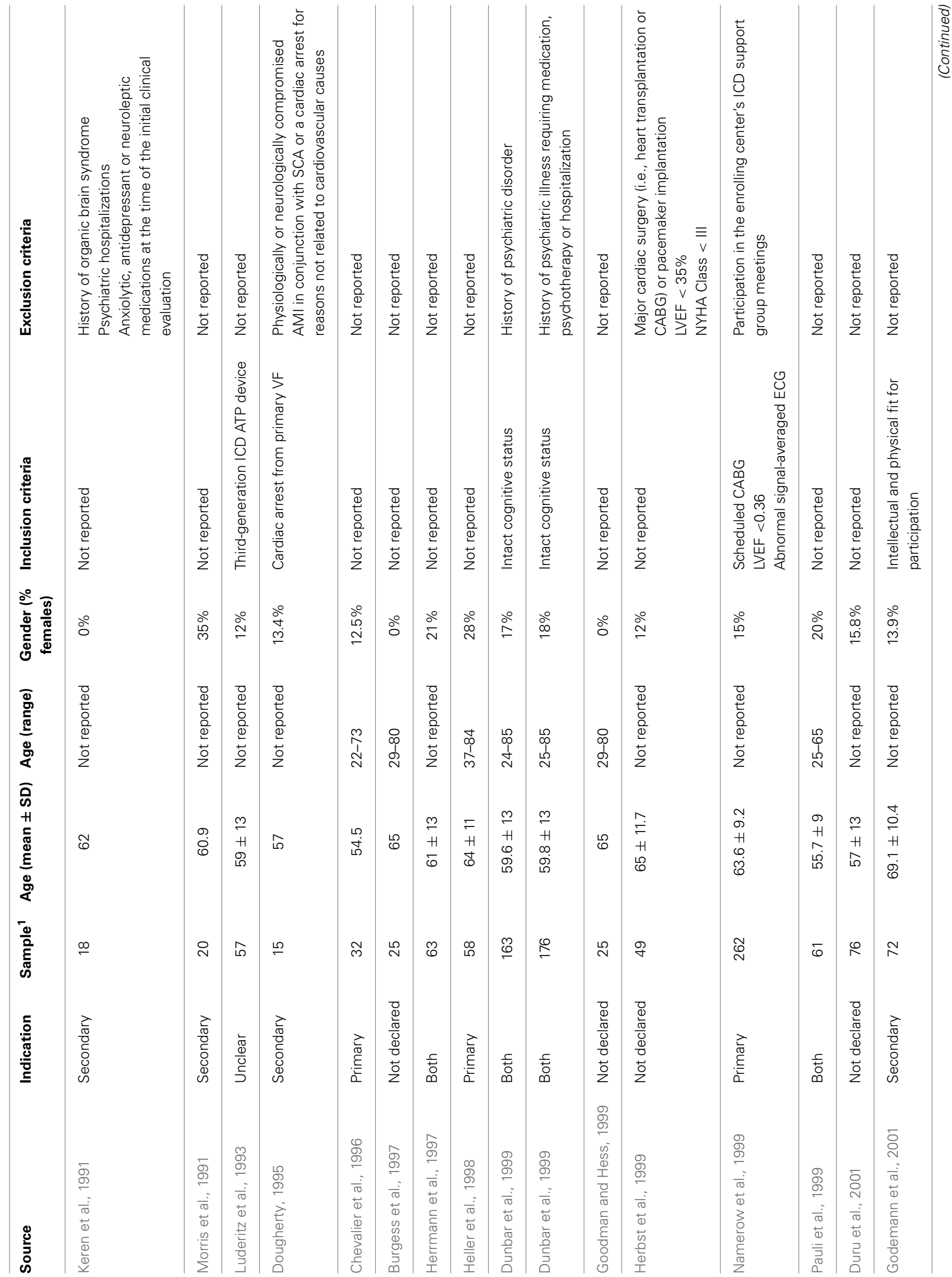




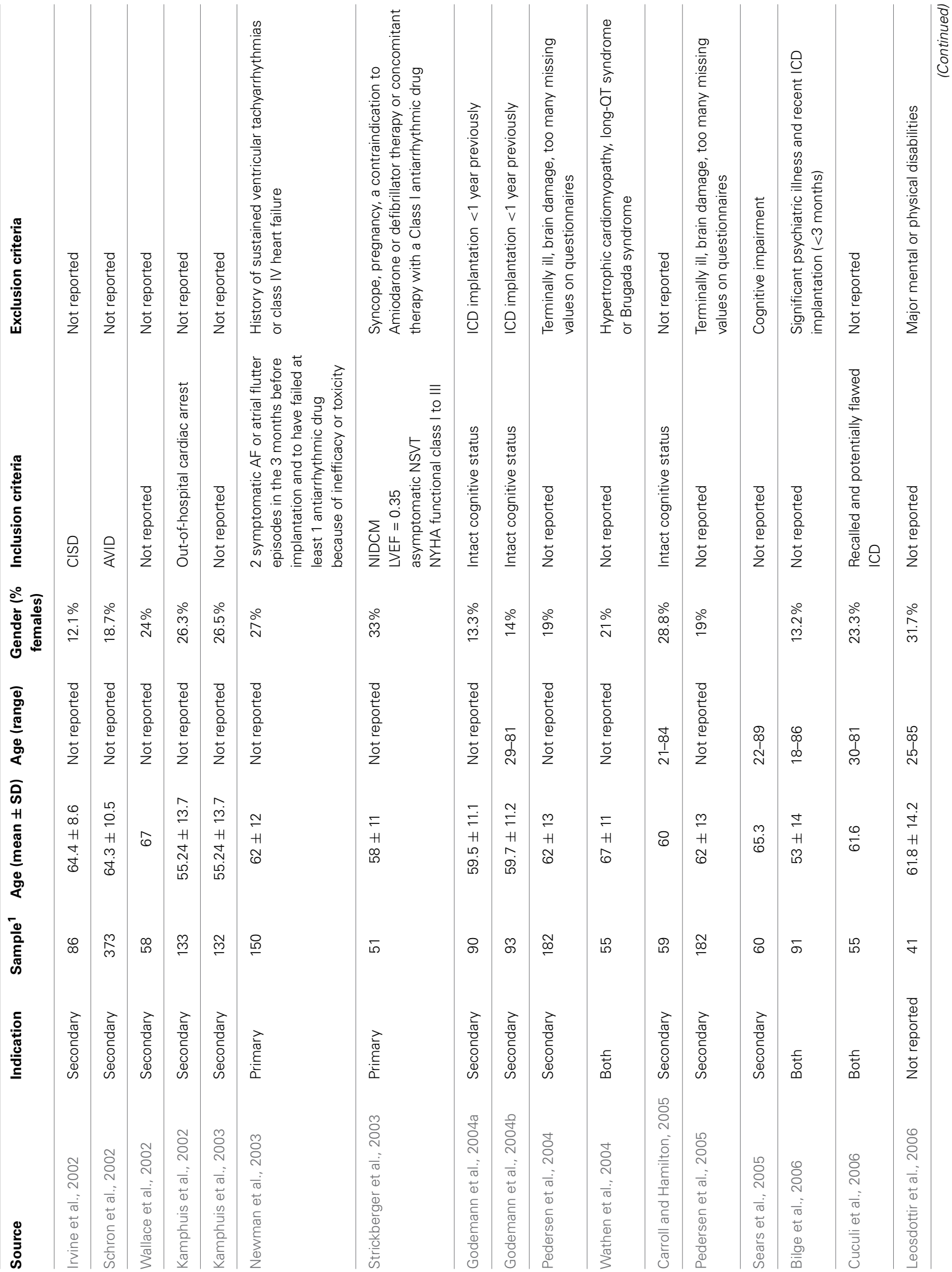




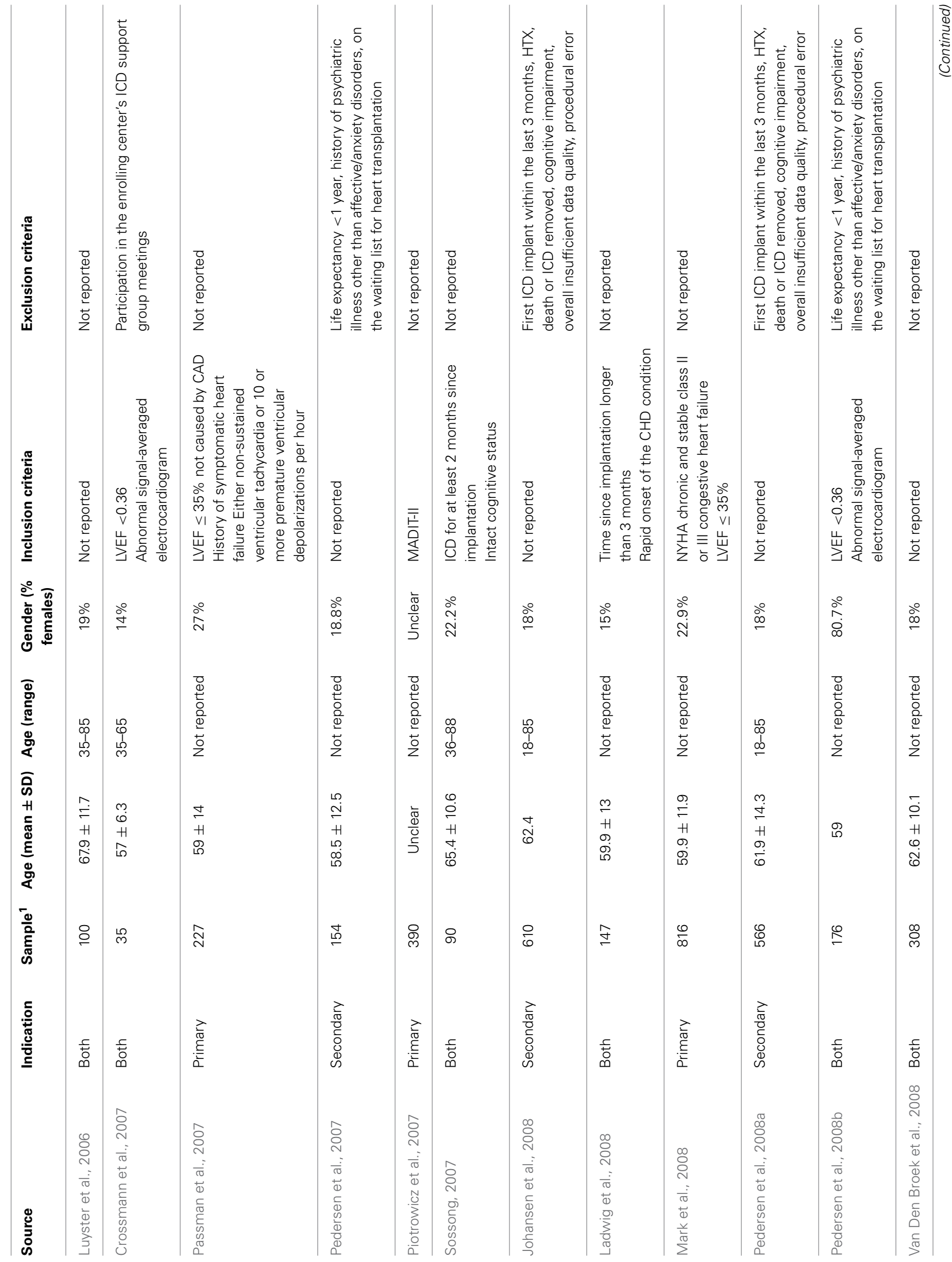




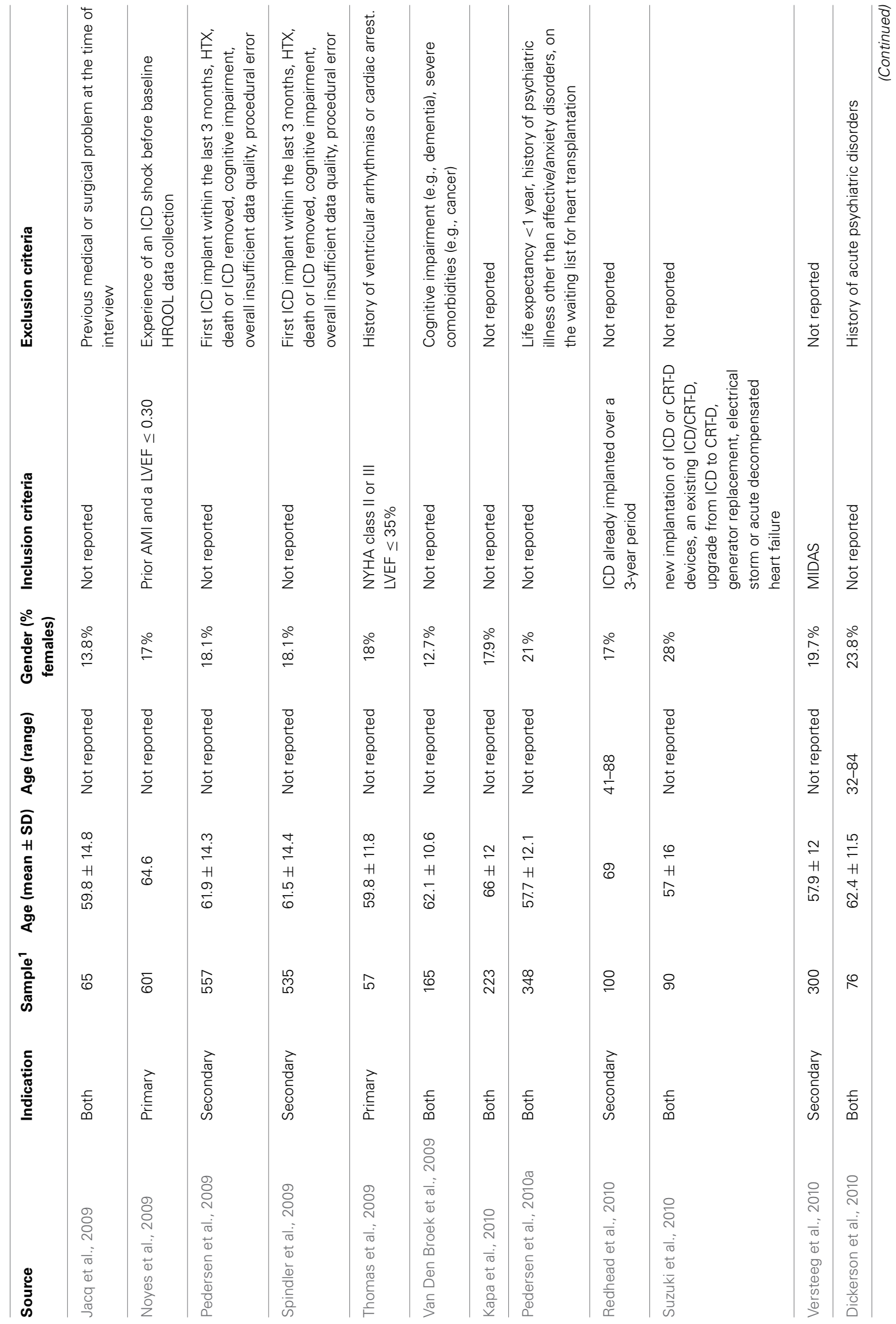


more shocks (Herrmann et al., 1997; Ladwig et al., 2008; Suzuki et al., 2010), while three studies grouped also patients who had received electrical storms (Kapa et al., 2010; Redhead et al., 2010; Suzuki et al., 2010). Three studies operationalized ICD shocks in units of time. Morris et al. (1991) divided the number of delayed ICD shocks by length of follow-up (in months) to generate a frequency rate per unit of time; Jacq et al. (2009) divided the number of shocks received since implantation by the time elapsed since implantation (ratio shock) in order to take into account the significant difference in time elapsed since implantation between participants who did or did not experience ICD shock; Pauli et al. (1999) calculated the relative number of ICD shocks per year. Finally, six studies calculated the number of ICD shocks that were delivered within a fixed length of time or since last assessment (Kamphuis et al., 2003; Bilge et al., 2006; Mark et al., 2008; Noyes et al., 2009; Dickerson et al., 2010; Suzuki et al., 2010). In all the other studies, the absolute number of ICD shocks that each patient received was considered for the analysis.

\section{Outcomes}

The most prevalent outcomes are measures of anxiety, depression and health-related quality of life. In particular, anxiety was measured in 36 studies, depression in 30 studies and healthrelated quality of life (both mental and physical) in 29 studies. Anxiety and depression were mostly measured with self-report questionnaires. In only three studies (two of them used also a self-report questionnaire) anxiety was assessed with a clinical interview (Van Den Broek et al., 2008, 2009; Jacq et al., 2009), while depression was evaluated with a diagnostic interview in only one study (Jacq et al., 2009). With respect to the self-report measure of anxiety as an outcome of ICD shocks, the Hospital Anxiety and Depression Scale (HADS) was the most used psychometric questionnaire (13 studies out of 35 , i.e., the total number of studies that used a self-report measure of anxiety, used the HADS). The second most used measure is the Spielberger State-Trait Anxiety Inventory (STAI), which was used in ten studies. The remaining self-report questionnaires that were used to measure anxiety are the Hamilton Anxiety Scale (1 study), the Beck Anxiety Inventory ( 1 study) and the anxiety index of the Symptom Checklist 90 (1 study). The Hamilton Rating Scale for Anxiety was used in two of the three studies that assessed anxiety with a clinical interview. Differently, Jacq et al. (2009) used the Mini International Neuropsychiatric Interview. With respect to the self-report measure of depression as an outcome of ICD shocks, the Hospital Anxiety and Depression Scale (HADS) was again the most used psychometric questionnaire (13 studies out of 30, i.e., the total number of studies that used a self-report measure of depression, used the HADS). The second most used measure is the Beck Depression Inventory (version 1 or 2) which was used in 6 studies. The remaining self-report questionnaires that were used to measure depression are the Zung Self-Rating Depression Scale (1 study), the Centre for Epidemiologic Studies Depression Scale (1 study) and the depression index of the Symptom Checklist 90 (1 study). The only study that assessed depression symptoms with a clinical interview used the Mini International Neuropsychiatric Interview (Jacq et al., 2009). General mental disorders were assessed in four studies (Morris 
et al., 1991; Chevalier et al., 1996; Godemann et al., 2001, 2004a). All of them used a semi-structured psychiatric interview according to the DSM-III-R criteria. Health-related quality of life was mostly measured with the SF-36 (15 studies) and the SF-12 (4 studies). Few other studies used the Health Utility Index 3 (Noyes et al., 2009), the Health Complaints Scale (Van Den Broek et al., 2009), the RAND-36 Health Survey (Kamphuis et al., 2002, 2003), the Ferrans and Powers Quality of Life Index (Carroll and Hamilton, 2005; Sossong, 2007; Dickerson et al., 2010), the General Health Questionnaire and the Icelandic Quality of Life Questionnaire (Leosdottir et al., 2006), the RAND-38 Mental Health Inventory and the Nottingham Health Profile (Irvine et al., 2002), and the Quality of Well Being Schedule (Strickberger et al., 2003). Further psychological outcomes are Post-Traumatic Stress Disorder (PTSD) or PTSD symptomatology, ICD acceptance and ICD concerns. PTSD was evaluated in five studies. The Impact of Event Scale-R was used in three studies (Ladwig et al., 2008; Kapa et al., 2010; Von Känel et al., 2011), while the Posttraumatic Stress Diagnostic Scale was administered in the other ones (Versteeg et al., 2010; Habibovic et al., 2012). ICD acceptance was analyzed as an outcome of ICD shocks in three studies (Pedersen et al., 2008a; Spindler et al., 2009; Keren et al., 2011). The Florida Patient Acceptance Survey was used in all of them. Finally, ICD concerns were assessed as an outcome of ICD shocks in two studies (Spindler et al., 2009; Van Den Broek et al., 2009). The ICD Concerns questionnaire was used in both ones.

\section{Timing of outcome assessment and follow-up}

Included studies vary a lot with respect to the timing of outcome assessment and follow-up. The first sharp distinction concerns study design. However, even considering cross-sectional and prospective studies separately, a large amount of variability remains in each category. In real cross-sectional studies, in which patients were assessed only once, a great heterogeneity in time from ICD implantation was observed both within and between studies. For example, the average of the mean times from ICD implantation across the 19 cross-sectional studies that reported time data on a continuous scale is 32 months with a SD of 18.2 (range: -60 ). The briefer mean time from ICD implantation was found in Namerow et al.' study (1999), while the longer one was found in Pedersen, Spindler, Johansen and Mortensen study (2009). In Jacq et al.'s study (2009), mean time from ICD implantation was divided between patients who received 1 or more shocks (37.4 months \pm 31.9 ) and patients who did not receive any shock (17.9 months \pm 16 ), while in 2 studies (Bilge et al., 2006; Redhead et al., 2010) patients were divided into multiple sub-groups according to fixed time intervals. In prospective studies, in which patients were assessed at least twice along the follow-up (repeated measures), differences and heterogeneities were observed in four factors: (1) baseline assessment (before ICD implantation or after ICD implantation); (2) time before ICD implantation; (3) timing of repeated measurements from ICD implantation; (4) length of follow-up. Baseline was clearly assessed before ICD implantation in 14 studies, but in only 3 out of them the baseline time-point was explicitly reported, i.e., 1 day before ICD implantation (Pedersen et al., 2007, 2008a, 2010a). However, these 3 studies are not independent because patients who comprised the three samples participated in the same study (MIDAS-Mood and personality as precipitants of arrhythmia in patients with an ICD: A prospective Study). Baseline was assessed before ICD implantation also in other 3 studies but not for all participants, some of whom were evaluated just after the implantation before hospital discharge (Dunbar et al., 1999; Irvine et al., 2002; Suzuki et al., 2010). Baseline was clearly assessed after ICD implantation in 8 studies but the timing of first assessment was highly heterogeneous both between and within them. For example, in some studies patients were evaluated few days after ICD implantation or at hospital discharge, while in other studies patients were firstly assessed after months from surgery. Finally, if baseline assessment was performed before or after the ICD implantation was impossible to establish in three studies because the respective articles do not report sufficient information. Prospective studies are quite heterogeneous also with respect to the number and timing of repeated measurements from ICD implantation and length of follow-up. For example, in only 19 out of 28 studies patients were followed for at least 12 months (see Table 2 for details).

\section{Statistical analysis}

Last but not least, studies vary quite a lot with respect to the statistical analyses that were performed to test the effect of ICD shocks on patients' psychological health and quality of life. Clearly, much of this heterogeneity is explained by the ways outcomes and ICD shocks were operationalized and also by study designs. However, two main analytical solutions were identified: (1) classifying patients in two or more shock-groups in accordance with different numerical criteria and testing the simple or adjusted effect of such dichotomized or categorized shock variable by univariate or multivariate analyses and (2) regressing outcome on number of shocks by multivariate regression analyses. Furthermore, in few studies patients were classified in different outcome-groups according to criteria such as psychiatric diagnoses, outcome change patterns or outcome distribution cut-offs and then compared on number of shocks. Finally, in only two studies intra-individual changes from pre-shock to post-shock assessments were analyzed by hierarchical regression models.

The heterogeneity of analytical approaches can be further explained by three factors: (1) the outcome variable scale (dichotomous, dichotomized or continuous); (2) the operationalization of ICD shocks (see previous paragraph) and (3) the number and kind of covariates/predictors that were entered into the statistical models. A fourth factor that pertains only to multivariate regression models concerns the importance of the ICD shock variable within the analysis. In fact, some of the studies that were included in the review did not handle the ICD shock variable as the main explaining factor but treated it as a potential covariate or controlling predictor. In these studies, the leading role was given to other psychological or medical factors (for example, type-D personality, concerns about the ICD, device acceptance and disease severity) and the ICD shock variable was mainly used as a competing predictor in the statistical explanation of patients' psychological distress. 

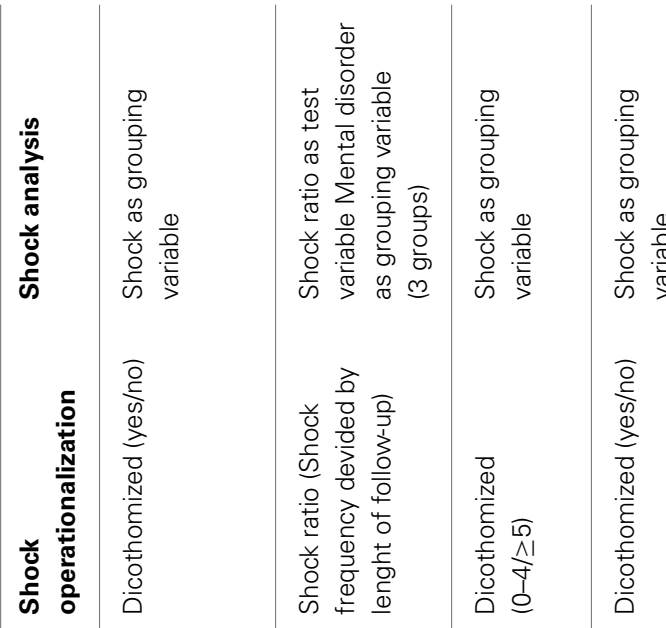

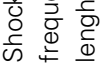
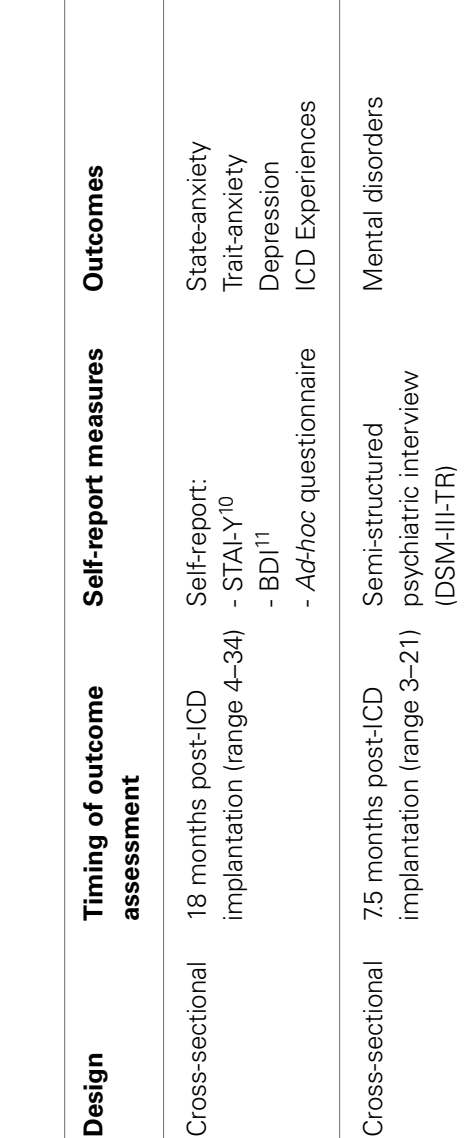

ڤั
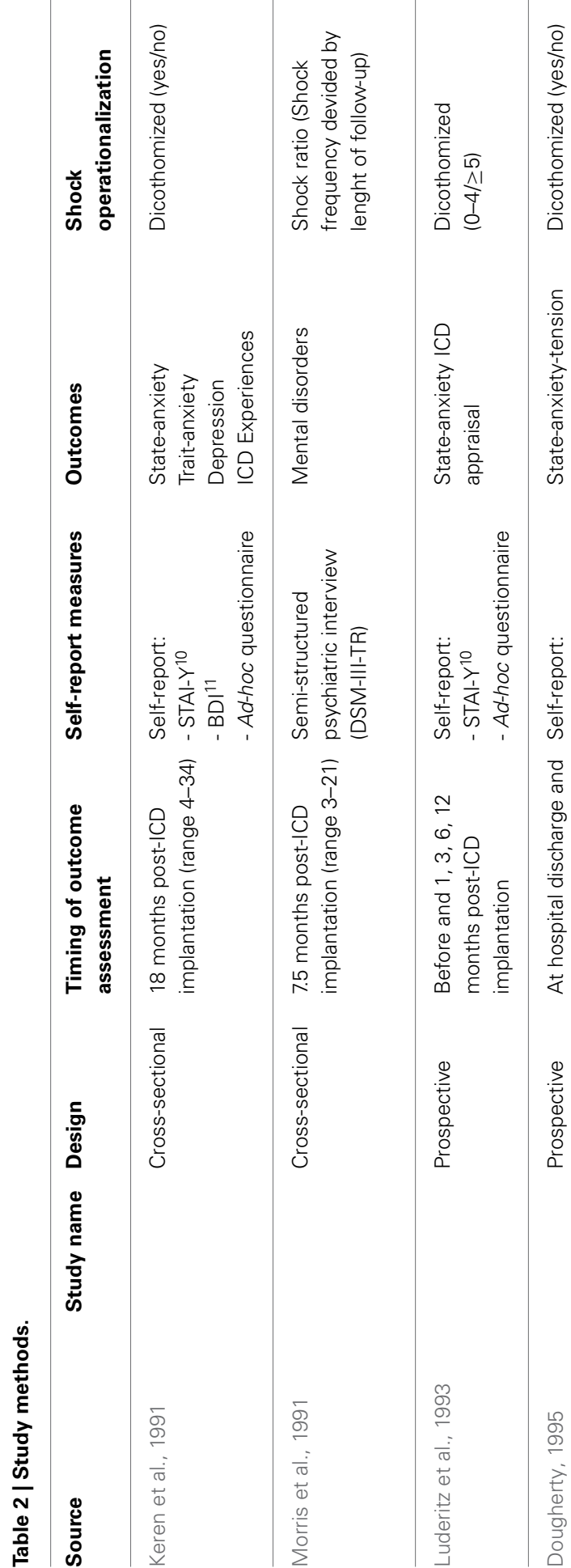

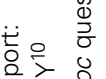

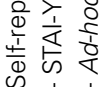
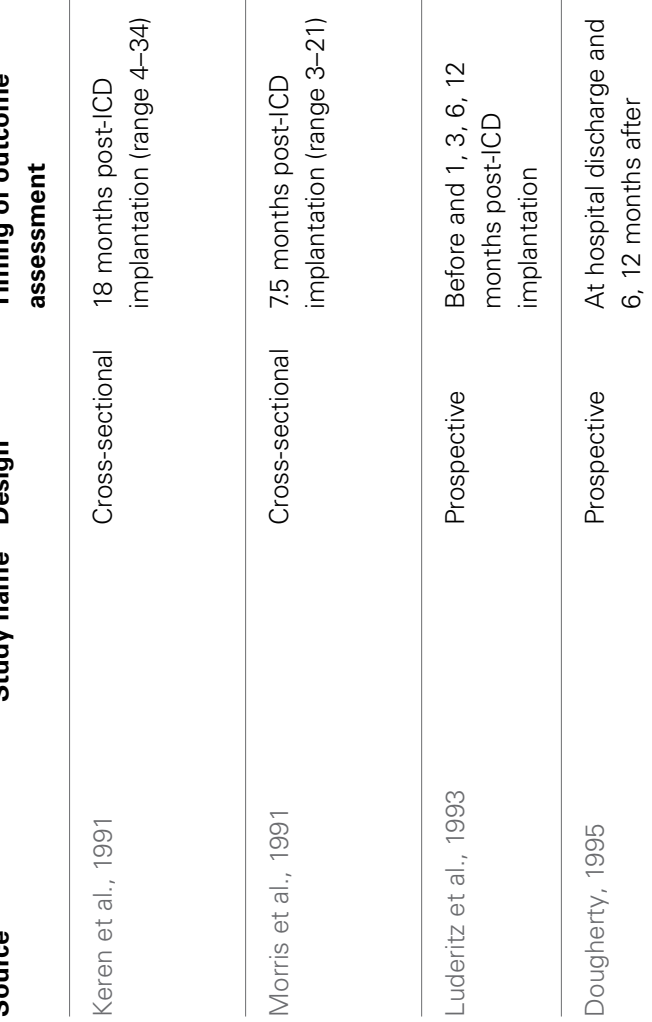
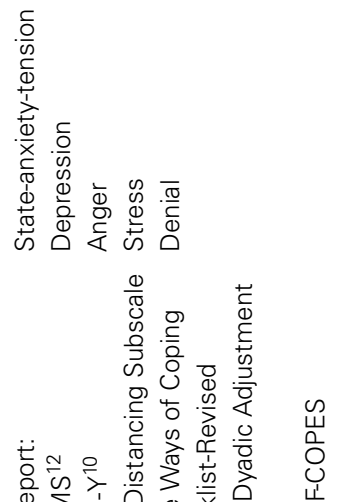

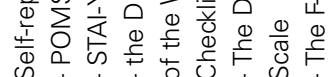

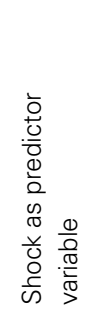

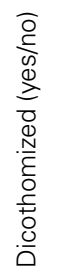

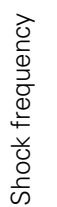
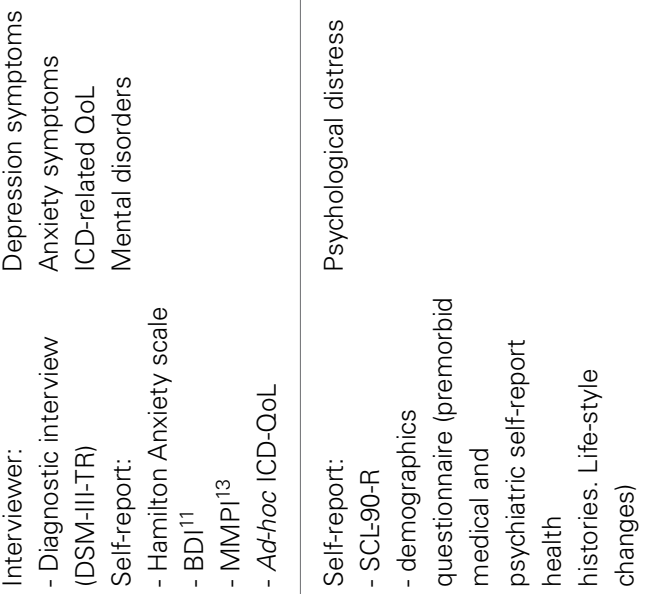

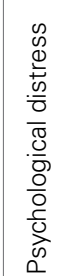

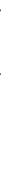

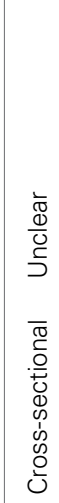

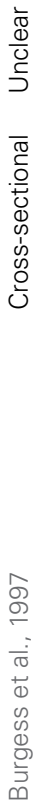




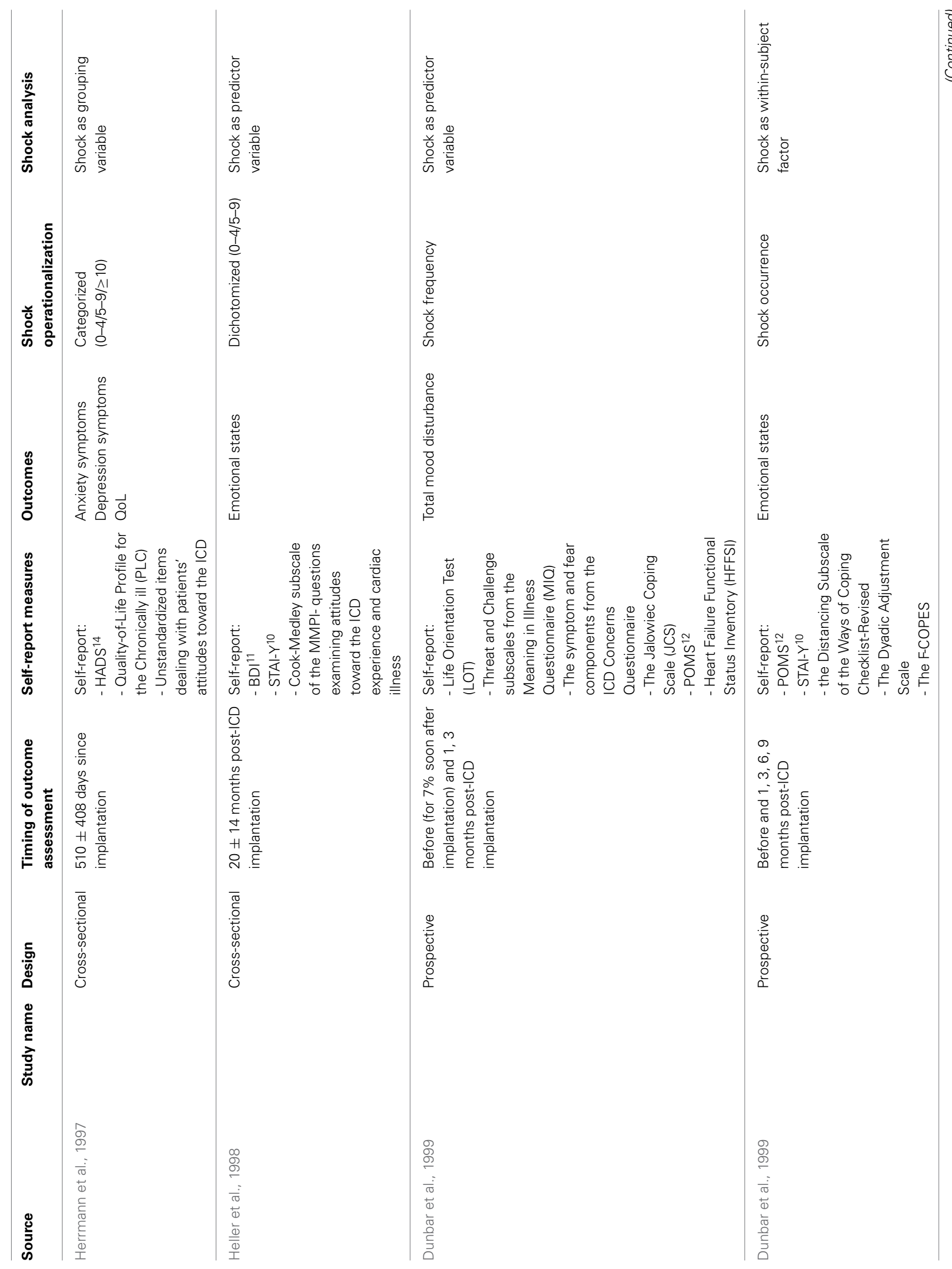




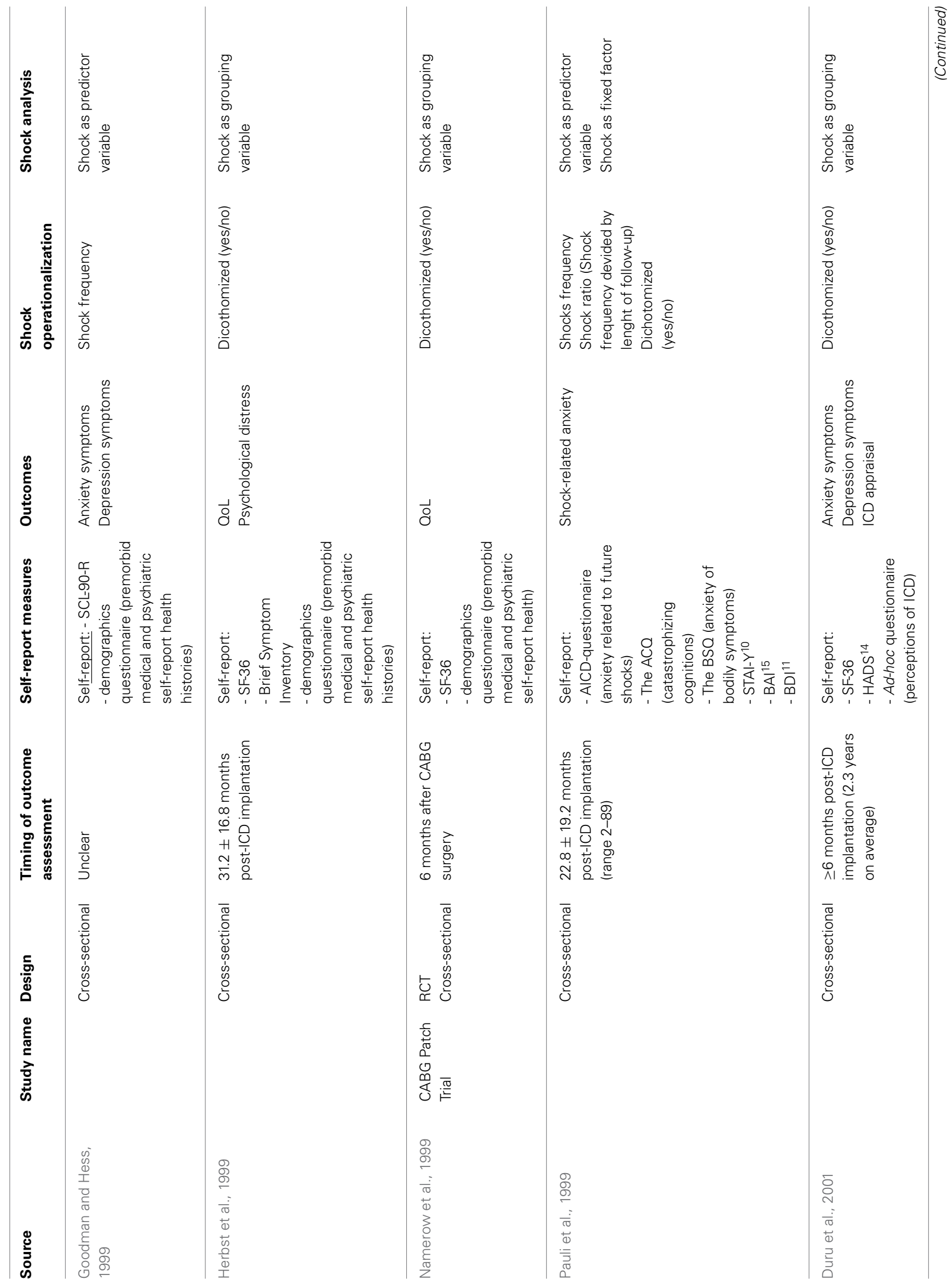




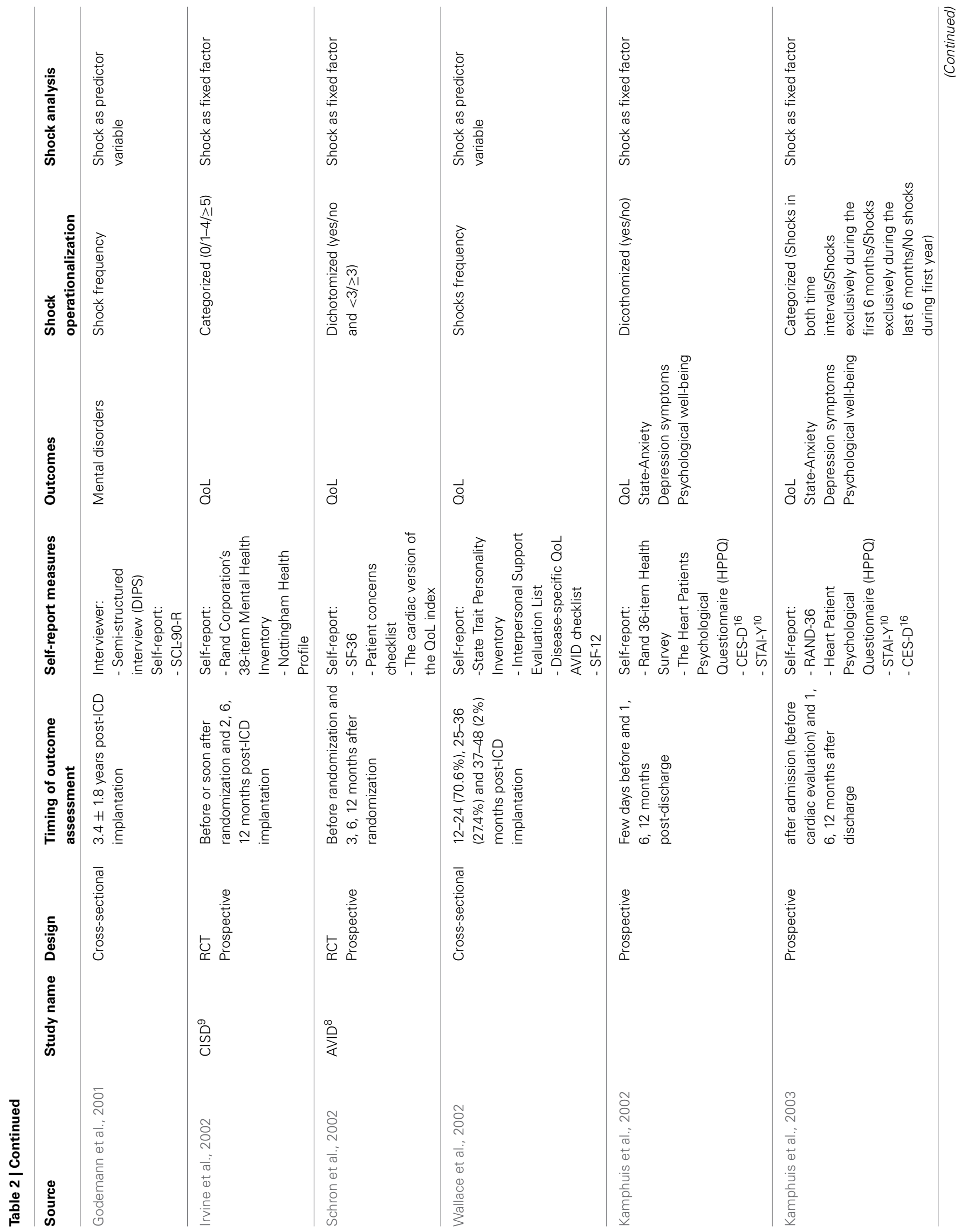




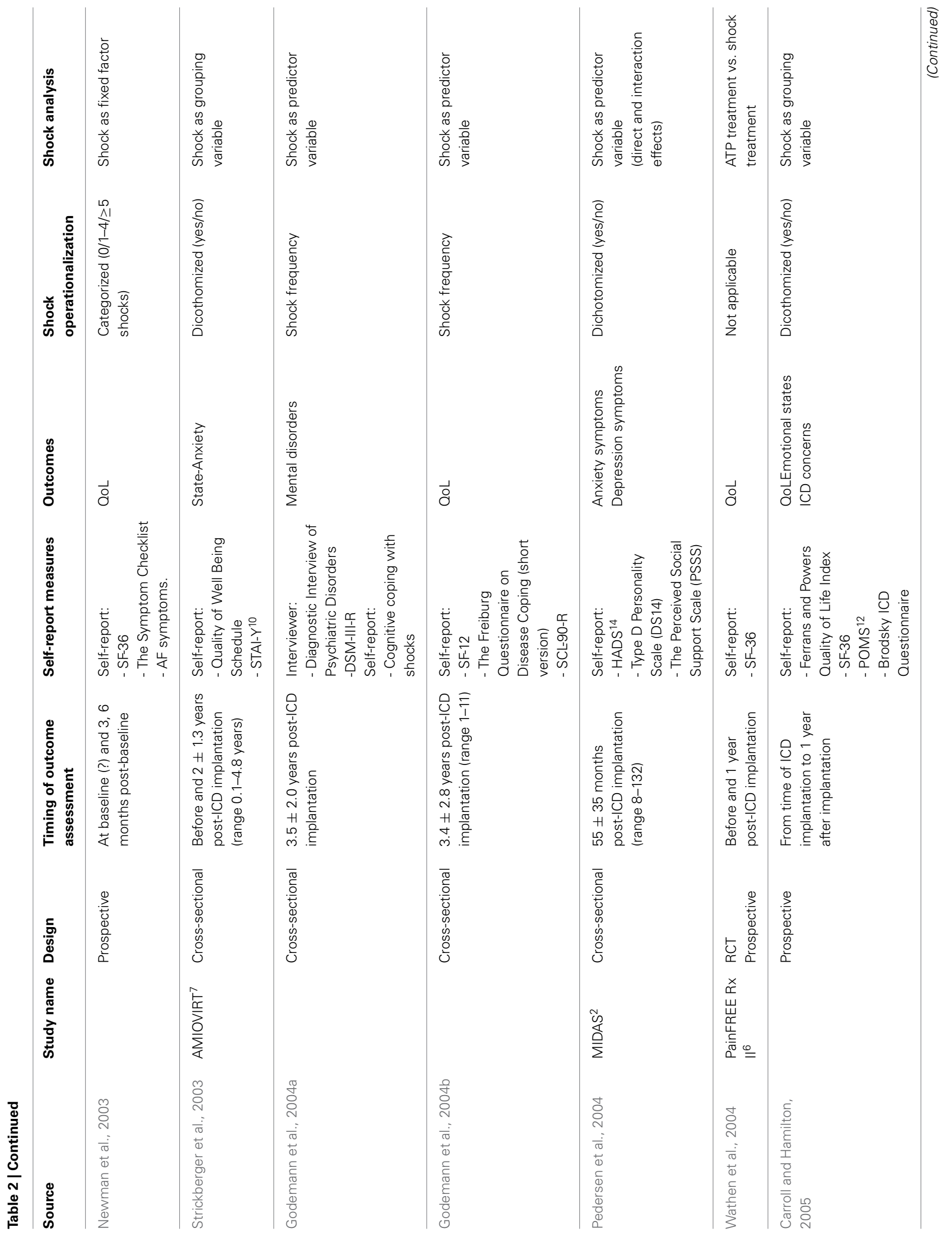




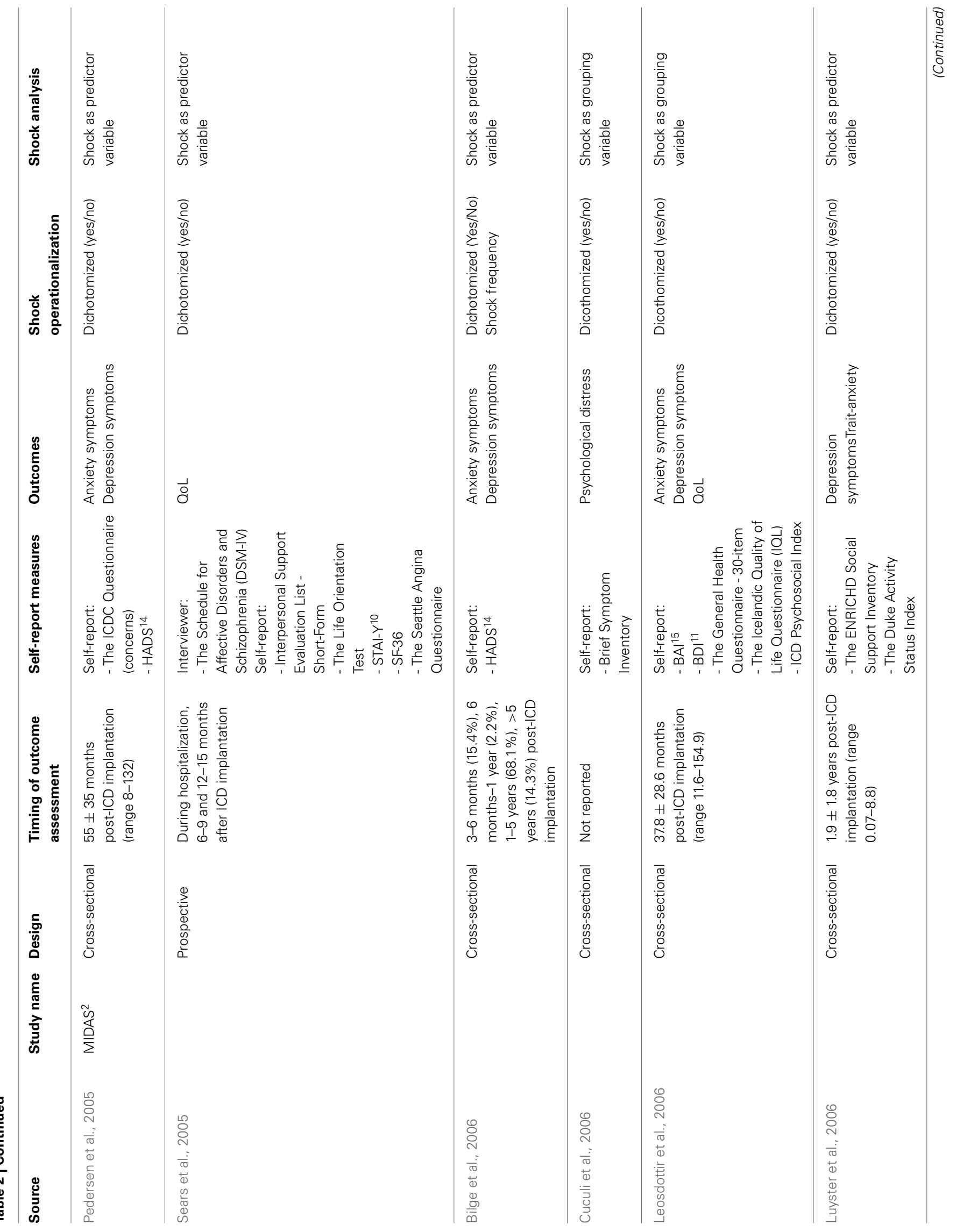




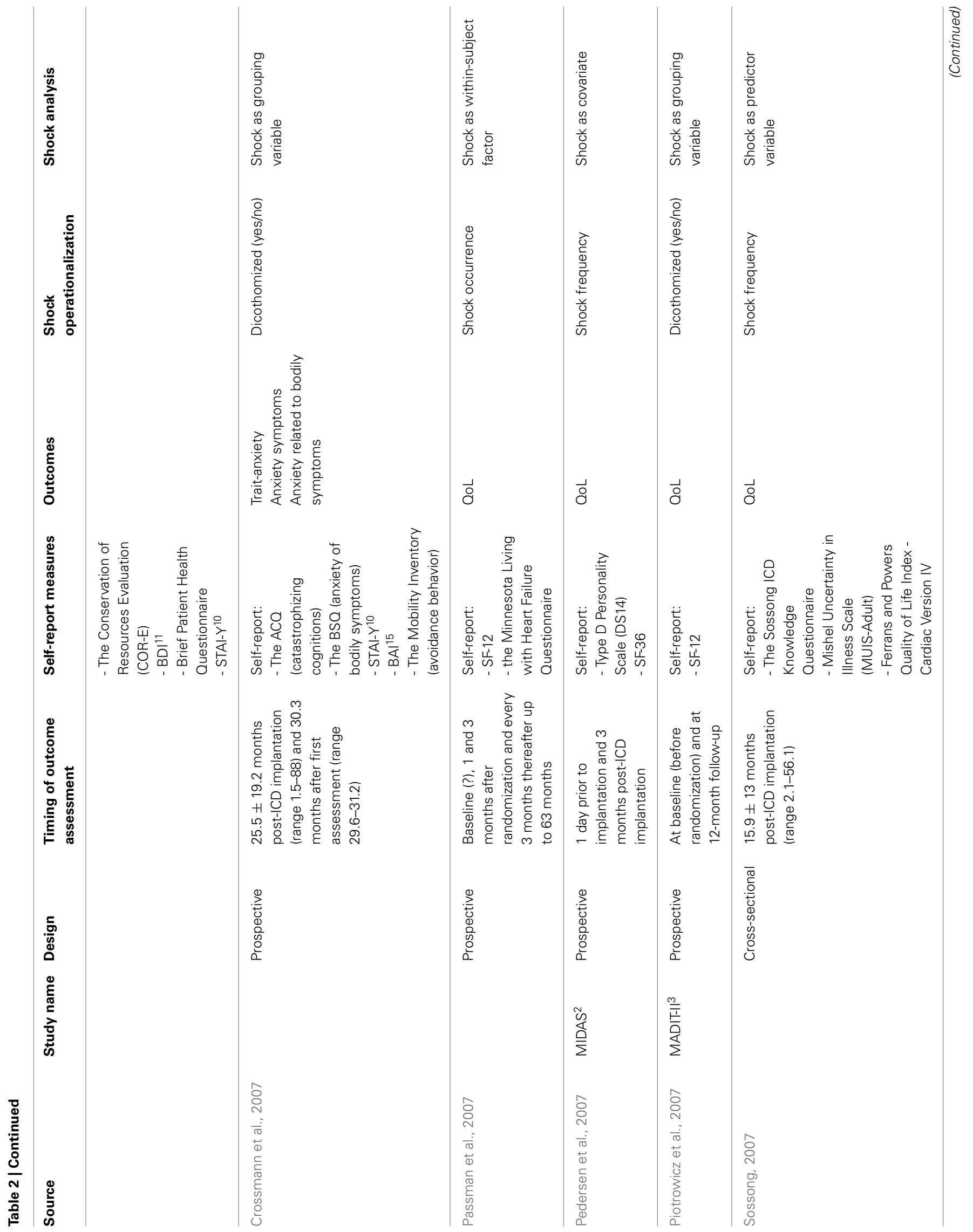




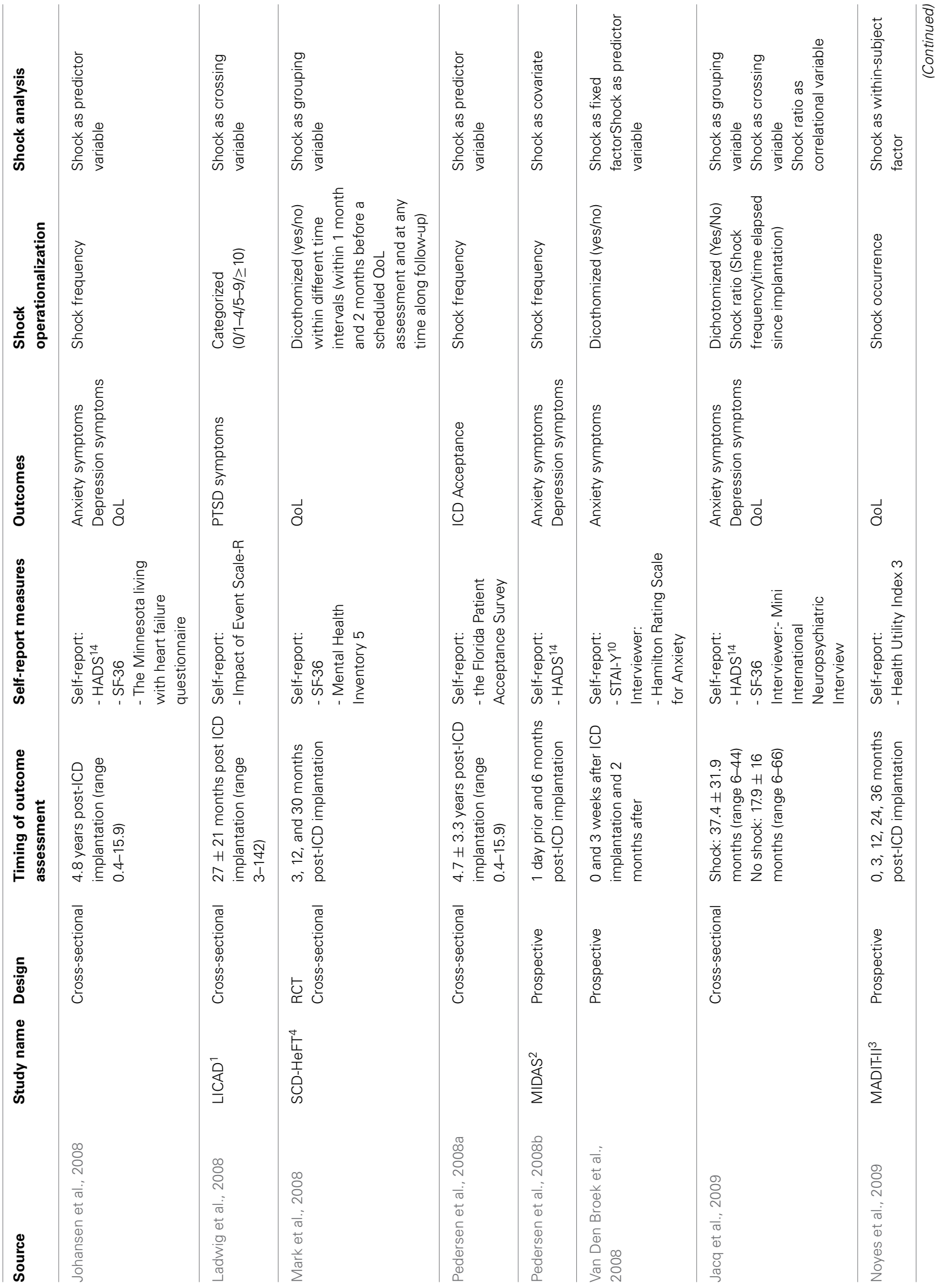



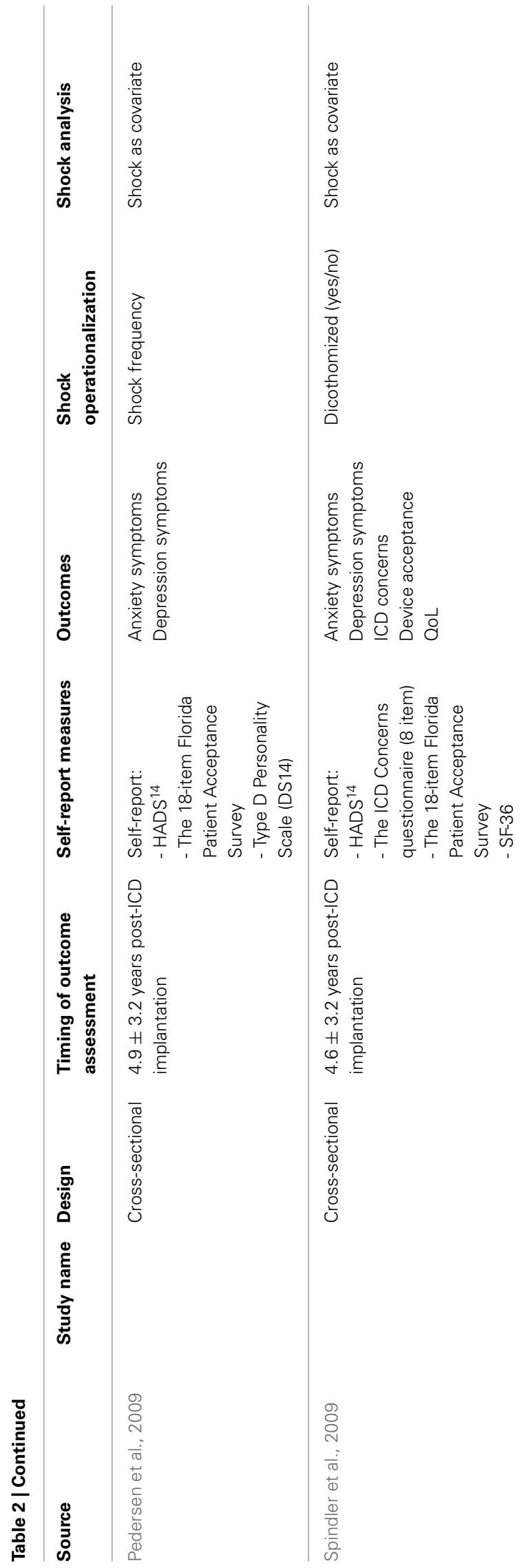

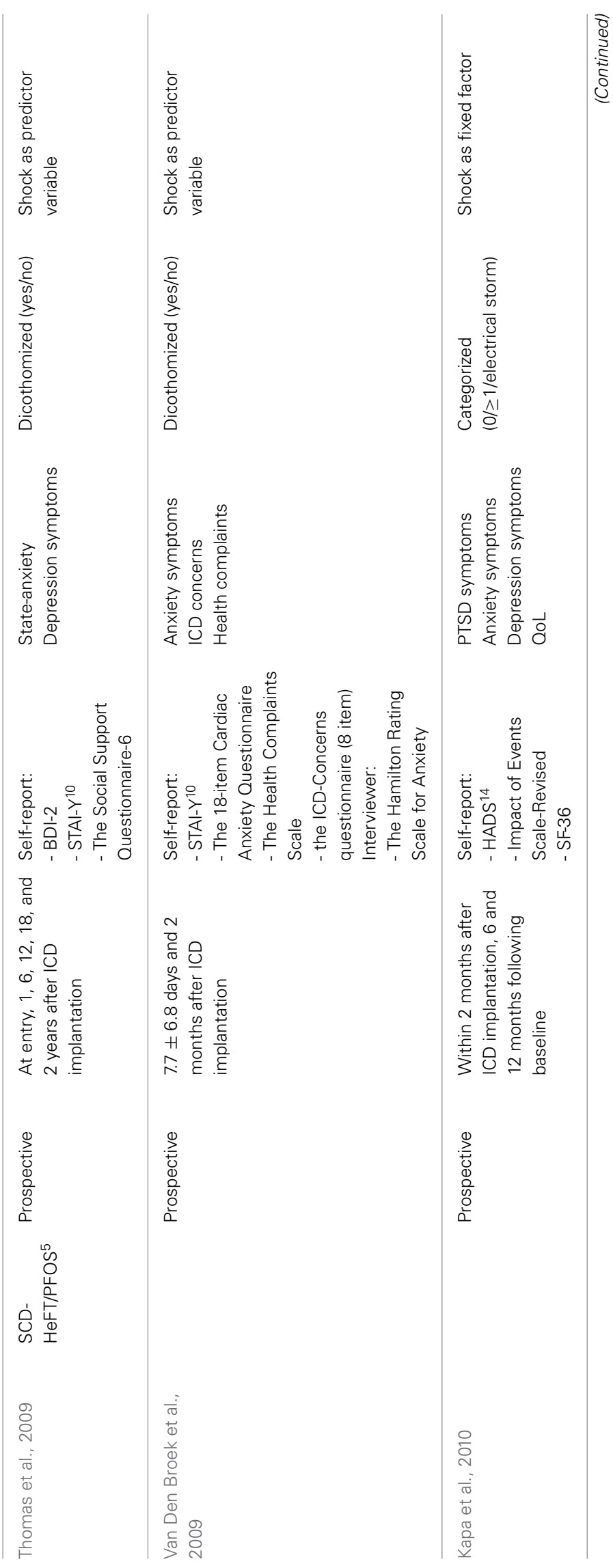




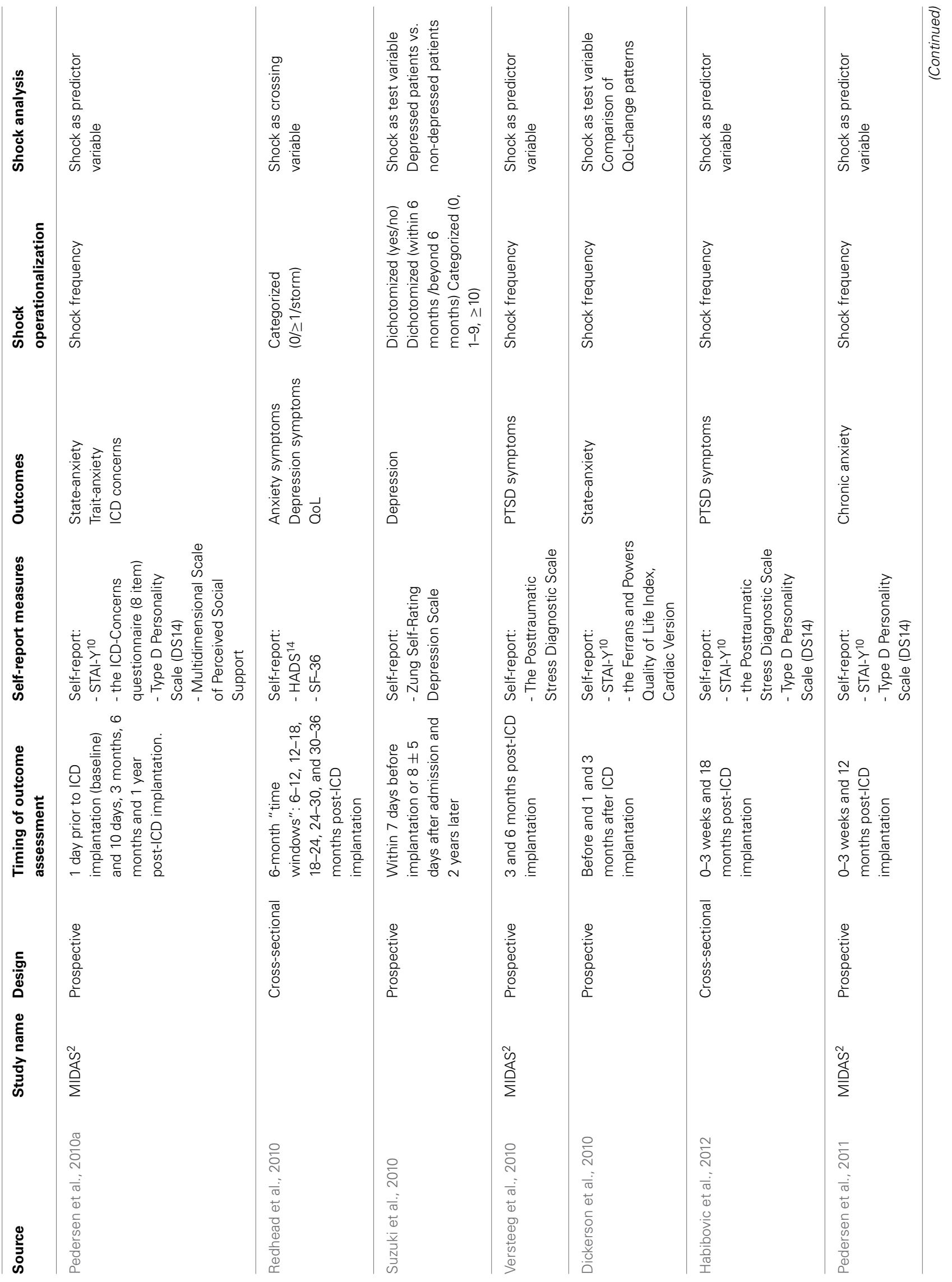




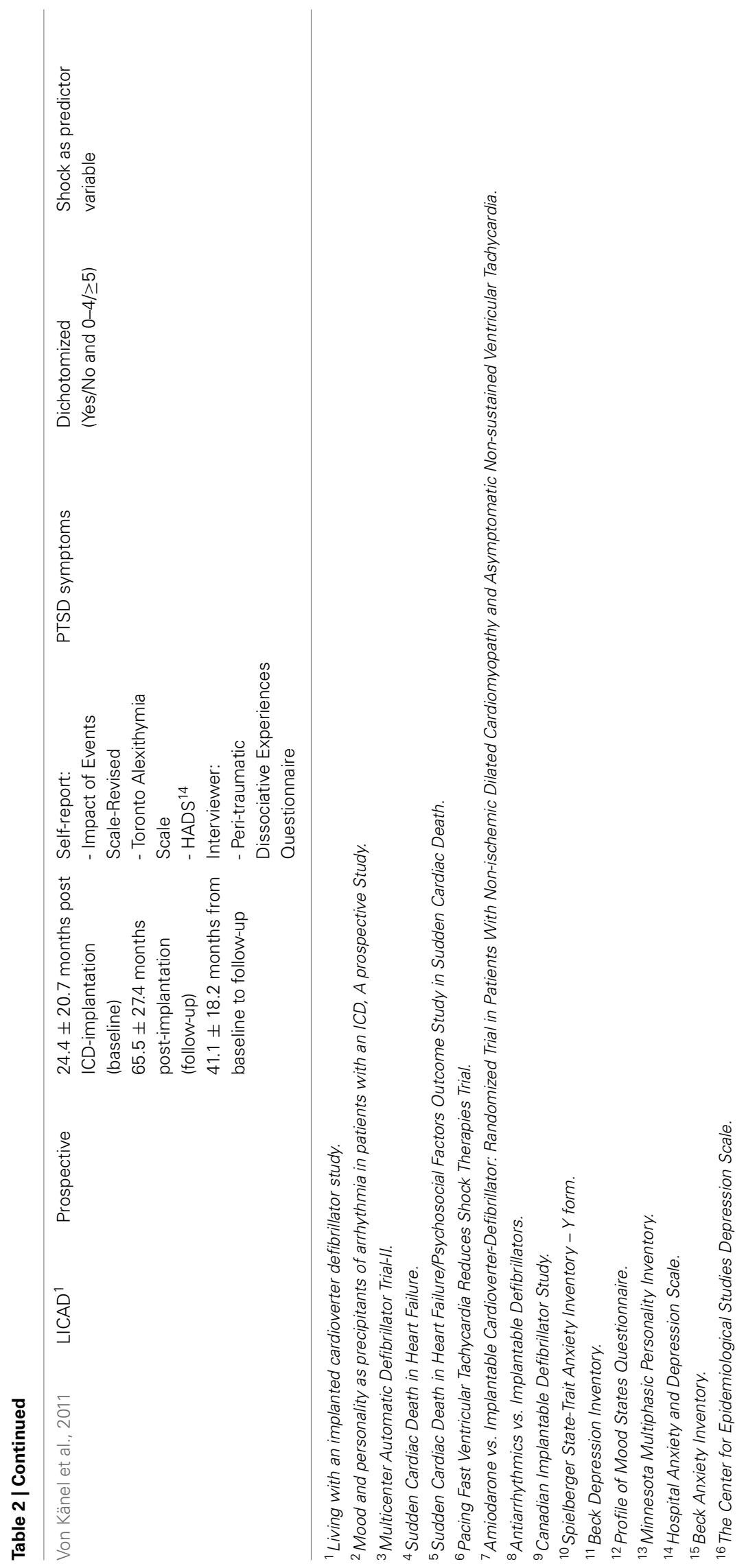




\section{RISK OF BIAS WITHIN STUDIES}

All papers that were included in the review were screened in search of some potential biases that could affect the validity of results. In particular, we searched for the systematic biases that can affect the internal validity of cross-sectional and cohort studies. In this kind of non-randomized studies, the major threat to internal validity concerns all the systematic differences that may exist between groups over and beyond the difference determined by the factor of interest and that may confound its effect. One of the methods that can protect against this bias consists in statistically controlling for the effects of all confounding variables that are related to the outcome and/or to the factor. A further method consists in matching subjects between groups according to some variables (for example, age, sex, type of heart disease, LVEF, NYHA Functional Class, etc.) but this procedure was used in only one study (Keren et al., 1991). All the other studies that attempted to reduce the risk of such a bias used the multiple regression method (35 out of 60 ). However, the number and kind of confounding variables that were selected and controlled for vary significantly across studies. The effect of the ICD shock was indeed adjusted for heterogeneous confounders and this may partially explain why results are discordant. A further major threat to the internal validity of cross-sectional and cohort studies is the presence of the outcome of interest before the occurrence of the event that hypothetically causes it. This bias, when uncontrolled, may affect seriously the causal meaning of an association and, for example, may lead to the wrong conclusion that the ICD shock caused the development of psychological disorders when the reverse was true. The most robust method that may protect against this bias consists in starting the evaluation of patients quite before the ICD implantation and in collecting short-spaced repeated measures along the follow-up. This was fully accomplished in only 18 prospective studies, in which patients were evaluated for the first time few days before surgery. In all the other prospective studies, the baseline was assessed after the ICD implantation. Anyway, for the issue of the review, i.e., the critical appraisal of methods that were adopted in studies on the psychological effect of ICD shock, the most important part of the procedure is clearly the short-spaced timing of repeated measurements that, combined with the hierarchical analysis of intra-individual pre- to post-shock changes, represents for us the best methodology for enhancing the internal validity of cohort studies whose aim is to evaluate the negative effect of ICD shock on patient's health. Another method that was used in few studies consists in evaluating patients retrospectively. However, this approach is prone to biases (e.g., the recall bias and the response shift) that may affect seriously the validity and reliability of patients' responses and that should be avoided. According to the Newcastle-Ottawa checklist, further threats to the internal validity of cross-sectional and cohort studies are the self-reported exposure to the event, the self-reported assessment of outcome, the low validity and reliability of outcome measures and the incompleteness of data set. Except for this last bias, which may seriously affect the validity of results as much as the previous major ones, all the other items were considered minor threats because of their relative low and negligible impact on the validity of results.

\section{RESULTS OF STUDIES AND SUBGROUP ANALYSIS}

Because of the great heterogeneity that was observed in methods across the included studies, a statistical meta-analysis of effects and moderators was deemed unfeasible and was not performed. Further, no attempt was made to describe each study in a narrative manner because of two reasons: (1) the large number of studies that were included and (2) the review aim to focus mainly on methods and to explore cross-sectionally their effects on results. Hence, key methodological features and results of each study were only coded and tabulated (Tables 2, 3). For example, results were coded with 1 when a significant effect of ICD shock was found and with 0 otherwise. We established the statistical significance of effects only on the basis of final results (in studies where both bivariate and multivariate analyses were performed, we considered only the adjusted effects). A series of subgroup analyses according to study design, shock operationalization, shock analysis and multivariate controlling was then performed only on outcomes for which at least 20 studies were available (twenty units were deemed sufficient to test cross-sectional associations between methodological factors and results). Findings are described in the following paragraphs for each outcome of interest.

\section{Anxiety}

Patients' anxiety was assessed as an outcome in 35 studies and it was mainly measured by self-report questionnaires. In RCTs that were included in the review, anxiety was never measured. A statistically significant effect of ICD shocks on self-reported anxiety was found in 17 studies, while a significant effect of shocks on interviewer-rated anxiety was found in only 1 study out of 3 . Subgroup analyses (Fisher's exact test) did not demonstrate any significant association between the methodological factors and the statistical significance of the shock effect on anxiety.

\section{Depression}

Patients' depression was assessed as an outcome in 29 studies and, as for anxiety, it was mainly measured by self-report questionnaires. Even depression was never measured in the RCTs included in the review. A statistically significant effect of ICD shocks on self-reported depression was detected in 10 studies, while a nonsignificant result was found in the only study in which depression was rated by a clinical interview. Subgroup analyses did not demonstrate any significant association between the methodological factors and the statistical significance of the shock effect on depression.

\section{Health-related quality of life}

Patients' health-related quality of life was assessed as an outcome in 30 studies and was always measured with self-report questionnaires. In most studies, both mental and physical components were evaluated, while in few studies only mental health (4 studies) or physical health (3 studies) were evaluated. With respect to mental health or psychological well-being, a statistically significant effect of ICD shock was found in 12 studies out of 27, while a statistically significant effect of ICD shock on physical health was detected in 11 studies out of 26 . Subgroup analyses did not 


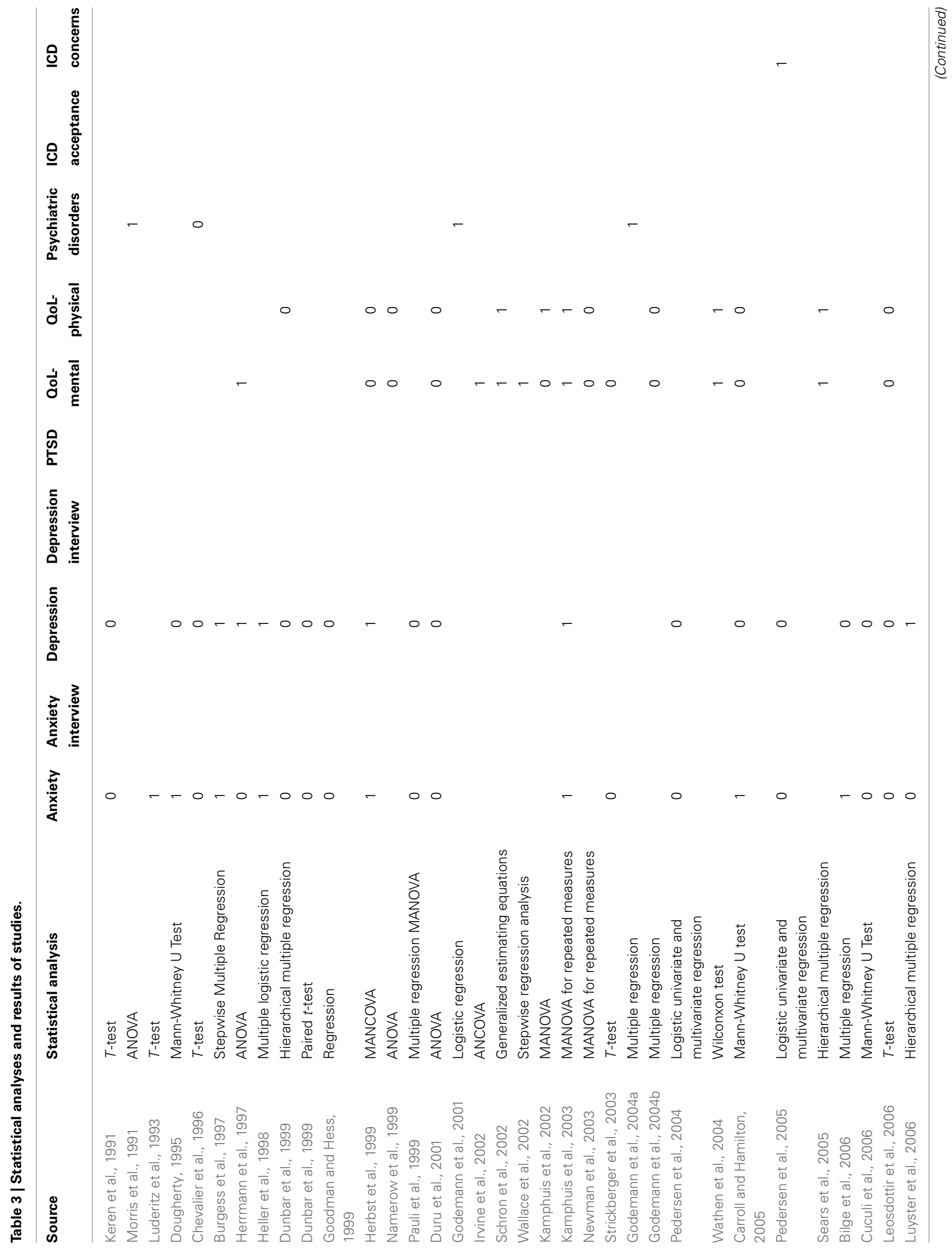




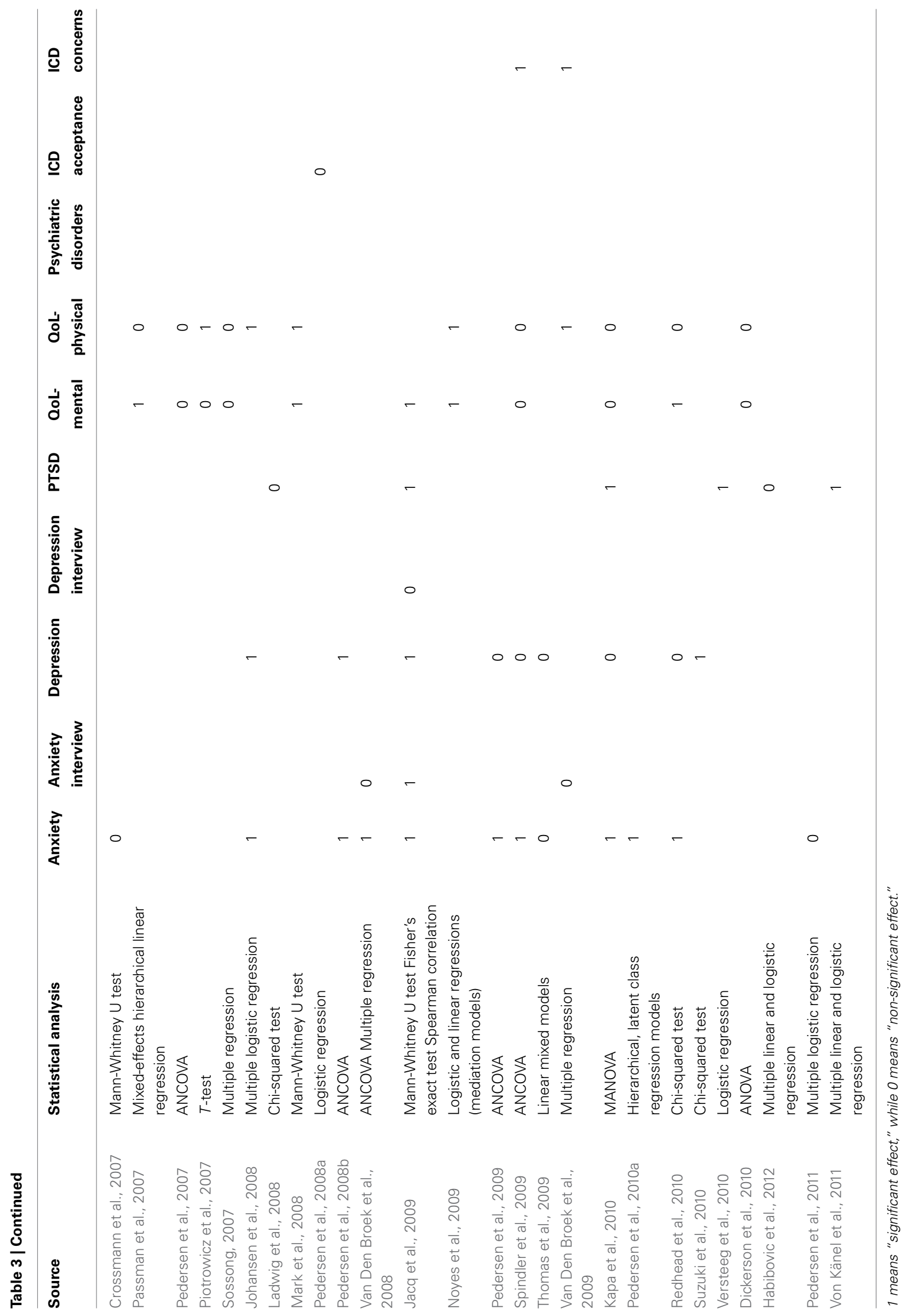


demonstrate any significant association between the methodological factors and the statistical significance of the shock effect on quality of life.

\section{Post-Traumatic Stress Disorder (PTSD)}

PTSD or PTSD symptoms were assessed as outcomes in five studies and were always measured with self-report questionnaires. A statistically significant effect of ICD shocks was found in 3 studies.

\section{Psychiatric disorders}

In four studies the effect of ICD shocks was assessed on psychiatric diagnosis of mental disorders and in 3 out of them the effect was statistically significant.

\section{ICD acceptance and concerns}

ICD acceptance was assessed as an outcome in 1 study but no significant effect of ICD shocks was found, while ICD concerns were measured in 3 studies and the effect of ICD shocks was statistically significant in all of them.

\section{DISCUSSION}

The critical appraisal of the mixed evidence concerning the relationship between ICD shocks and patient-centered outcomes (mainly QoL, anxiety and depression) is the main content of three recently published papers (Pedersen and Van Den Broek, 2008; Pedersen et al., 2010b; Sears and Kirian, 2010). Despite slightly different paradigmatic views on the relative importance of ICD shocks within the group of the numerous factors that may negatively influence the psychological adaptation and well-being of implanted patients, the authors agree that the heterogeneity of designs and methods across studies is most likely to account for the mixed findings.

The quasi-quantitative results of our review do not support this hypothesis. In particular, study design (cross-sectional vs. prospective studies), shock operationalization (the way ICD shocks were operationalized/quantified), shock analysis (the way the effect of ICD shocks was tested) and control for confounding (bivariate vs. multivariate analyses) were examined in votecounting subgroup analysis, but statistical evidence was null for each of them.

As already noted by Pedersen et al. in a recent viewpoint (2010b), results are mixed even in the subgroup of RCTs. Hence, it seems that the statistical significance of the ICD shock effect on patients' QoL (anxiety and depression were not measured in RCTs) does not depend strictly on sample size. Furthermore, contrary to the hypothesis that a dose-response relationship may exist between the number of shocks and QoL, with only patients experiencing $\geq 5$ shocks being at risk for impaired QoL (Irvine et al., 2002; Pedersen et al., 2010b), studies that categorized the shock variable in classes of increasing shock incidence (e.g., 0-4 vs. 5-9 vs. $\geq 10$ shocks) did not show consistent significant results in any of the outcomes of interest.

However, such null evidence is far from being conclusive. This systematic review shows clearly that methods are very heterogeneous across studies and suggests that such methodological differences should be considered in a multivariate fashion rather than bivariately. However, subgrouping the included studies in a multivariate manner is unfeasible because it would parcel out studies in a number of cells that would be too small for valid statistical analysis.

Subgroup analyses were not performed on the few studies that evaluated the effect of ICD shock on PTSD development or PTSD symptoms, psychiatric disorders, ICD acceptance and ICD concerns. With the exception of the five studies that assessed PTSD and whose results are mixed as well, the evidences pertaining to the psychiatric diagnosis of mental disorders (4 studies) and to ICD concerns (3 studies) are consistently significant and support the hypothesis that one or more ICD shocks may cause the development of a psychiatric disorder and the hypothesis that shocked patients have significantly more concerns about the ICD. However, the strength of the former evidences is low because the very few studies that tested the effect of ICD shock on mental disorders used a cross-sectional approach. In none of them patients were actually administered the psychiatric interview before ICD implantation and the mental disorders that were diagnosed long after implantation might have been already present before or immediately after, even before the occurrence of the first shock. Despite the severe limitations of a vote-counting approach, the attempt to explore whether methodological differences across studies account for the mixed findings of the literature on the effect of ICD shocks on patients' QoL, anxiety and depression was not vain because it allowed the full discovery of the wide and multiple heterogeneities that exist across studies. Furthermore, it allowed the discovery of severe methodological flaws, the most important of which are undoubtedly the cross-sectional design that was applied by the great part of studies and the multiple wrong ways that were used to operationalize shocks.

Our description is not comprehensive inasmuch as other hypothetical accounting factors were intentionally overlooked. Some information on demographics (age and sex), ICD indication (primary or secondary prevention) and both inclusion and exclusion criteria was extracted from studies and tabulated (Table 1), but any explorative attempt to meta-correlate them with the significance of the shock effect failed. However, in many of the studies that were included in this review, a variety of patient characteristics (demographic, clinical, psychological, etc.) was considered for explaining why, in some patients, QoL and psychological health deteriorate after ICD implantation. Such variables were also entered in multivariate analyses together with ICD shocks, but their effects on patient-centered outcomes were mainly examined as competitors of ICD shocks. Surprisingly, only one study tested the moderating effect of a patient characteristic (i.e., Type-D personality) on the relationship between shocks and psychological distress (anxiety and depression) (Pedersen et al., 2004). A significant interaction (Type-D $\times$ Shocks $\geq 1$ ) was found only for depression, i.e., ICD patients who received one or more shocks and had a type D personality (negative affectivity and social inhibition) reported an higher mean level of depression than ICD patients who received one or more shocks and had not a type $\mathrm{D}$ personality. However, this interesting result received no consideration in the discussion, probably because the authors were more concerned in looking beyond shocks toward other determinants such as the type-D personality. 


\section{CONCLUSIONS}

Clinical practice suggests that ICD shocks have a detrimental effect on patients' QoL and account for the development of anxiety and depression disorders. However, results of studies that have investigated this issue are discordant. The heterogeneity of designs and methods has been ascribed as the main reason for the discrepancy but our findings do not support such hypothesis.

The attempt to solve the problem with a quasi-quantitative approach was daring due to its severe limitations but no other meta-analytic approach was feasible. Regardless of this, the systematic review allowed us to look more clearly at studies and to paint a partial picture of the current status of research on the impact of ICD shocks on patient-centered outcomes.

We think that drawing firm statements about the short, mid and long-term impact of ICD shocks on patients' QoL and psychological well-being is an important matter both for the optimal clinical management of patients and for the adoption of new ICD programming strategies that eliminate or reduce ICD shocks. It is thus imperative that research on the psychological effects of ICD shocks goes further. Future studies should avoid the methodological flaws described in this review and should also consider that the relationship between ICD shocks and patient-centered outcomes may not be as straightforward as expected. Some other putative variables such as personality traits (e.g., Type D personality), coping skills and social support play surely a role and their effects on ICD patients' psychological health should be investigated also in interaction with the occurrence of shocks in order to know the profile of patients who might respond badly and focus treatment resources on them.

\section{REFERENCES}

Anderson, J. L., Hallstrom, A. P., Epstein, A. E., Pinski, S. L., Rosenberg, Y., Nora, M. O., et al. (1999). Design and results of the antiarrhythmics vs implantable defibrillators (AVID) registry. The AVID Investigators. Circulation 99, 1692-1699.

Bardy, G. H., Lee, K. L., Mark, D. B., Poole, J. E., Packer, D. L., Boineau, R., et al. (2005). Amiodarone or an implantable cardioverter-defibrillator for congestive heart failure. N. Engl. J. Med. 352, 225-237. doi: 10.1056/NEJMoa043399

Barnay, C., Taieb, J., and Morice, R. (2007). [Electrical storm]. Ann. Cardiol. Angeiol. 56, 183-187. doi: 10.1016/j.ancard.2007.08.003

Bilge, A. K., Ozben, B., Demircan, S., Cinar, M., Yilmaz, E., and Adalet, K. (2006). Depression and anxiety status of patients with implantable cardioverter defibrillator and precipitating factors. Pacing Clin. Electrophysiol. 29, 619-626. doi: $10.1111 /$ j.1540-8159.2006.00409.x

Burgess, E. S., Quigley, J. F., Moran, G., Sutton, F. J., and Goodman, M. (1997). Predictors of psychosocial adjustment in patients with implantable cardioverter defibrillators. Pacing Clin. Electrophysiol. 20, 1790-1795.

Burke, J. L., Hallas, C. N., Clark-Carter, D., White, D., and Connelly, D. (2003). The psychosocial impact of the implantable cardioverter defibrillator: a meta-analytic review. Br. J. Health Psychol. 8, 165-178. doi: 10.1348/135910703321649141

Buxton, A. E., Lee, K. L., Fisher, J. D., Josephson, M. E., Prystowsky, E. N., and Hafley, G. (1999). A randomized study of the prevention of sudden death in patients with coronary artery disease. Multicenter unsustained tachycardia trial investigators. N. Engl. J. Med. 341, 1882-1890. doi: 10.1056/NEJM199912163412503

Carroll, D. L., and Hamilton, G. A. (2005). Quality of life in implanted cardioverter defibrillator recipients: the impact of a device shock. Heart Lung. 34, 169-178. doi: 10.1016/j.hrtlng.2004.10.002

Chevalier, P., Verrier, P., Kirkorian, G., Touboul, P., and Cottraux, J. (1996). Improved appraisal of the quality of life in patients with automatic implantable cardioverter defibrillator: a psychometric study. Psychother. Psychosom. 65, $49-56$.
Connolly, S. J., Gent, M., Roberts, R. S., Dorian, P., Roy, D., Sheldon, R. S., et al. (2000a). Canadian implantable defibrillator study (CIDS): a randomized trial of the implantable cardioverter defibrillator against amiodarone. Circulation 101, 1297-1302. doi: 10.1161/01.CIR.101.11.1297

Connolly, S. J., Hallstrom, A. P., Cappato, R., Schron, E. B., Kuck, K. H., Zipes, D. P., et al. (2000b). Meta-analysis of the implantable cardioverter defibrillator secondary prevention trials. AVID, CASH and CIDS studies. Antiarrhythmics vs Implantable Defibrillator study. Cardiac Arrest Study Hamburg. Canadian Implantable Defibrillator Study. Eur. Heart J. 21, 2071-2078. doi: 10.1053/euhj.2000.2476 S0195668X0092476X [pii]

Crossmann, A., Pauli, P., Dengler, W., Kuhlkamp, V., and Wiedemann, G. (2007). Stability and cause of anxiety in patients with an implantable cardioverterdefibrillator: a longitudinal two-year follow-up. Heart Lung. 36, 87-95. doi: 10.1016/j.hrtlng.2006.08.001

Cuculi, F., Herzig, W., Kobza, R., and Erne, P. (2006). Psychological distress in patients with ICD recall. Pacing Clin. Electrophysiol. 29, 1261-1265. doi: 10.1111/j.1540-8159.2006.00523.x

Dickerson, S. S., Kennedy, M., Wu, Y. W., Underhill, M., and Othman, A. (2010). Factors related to quality-of-life pattern changes in recipients of implantable defibrillators. Heart Lung. 39, 466-476. doi: 10.1016/j.hrtlng.2009.10.022

Dougherty, C. M. (1995). Psychological reactions and family adjustment in shock versus no shock groups after implantation of internal cardioverter defibrillator. Heart Lung. 24, 281-291.

Dunbar, S. B., Jenkins, L. S., Hawthorne, M., Kimble, L. P., Dudley, W. N., Slemmons, M., et al. (1999). Factors associated with outcomes 3 months after implantable cardioverter defibrillator insertion. Heart Lung. 28, 303-315. doi: 10.1053/hl.1999.v28.a101052

Duru, F., Buchi, S., Klaghofer, R., Mattmann, H., Sensky, T., Buddeberg, C., et al. (2001). How different from pacemaker patients are recipients of implantable cardioverter-defibrillators with respect to psychosocial adaptation, affective disorders, and quality of life? Heart 85, 375-379. doi: 10.1136/heart.85.4.375

Godemann, F., Ahrens, B., Behrens, S., Berthold, R., Gandor, C., Lampe, F., et al. (2001). Classic conditioning and dysfunctional cognitions in patients with panic disorder and agoraphobia treated with an implantable cardioverter/defibrillator. Psychosom Med 63, 231-238. doi: 10.1097/00006842-200103000-00006

Godemann, F., Butter, C., Lampe, F., Linden, M., Schlegl, M., Schultheiss, H. P., et al. (2004a). Panic disorders and agoraphobia: side effects of treatment with an implantable cardioverter/defibrillator. Clin. Cardiol. 27, 321-326. doi: $10.1002 /$ clc.4960270604

Godemann, F., Butter, C., Lampe, F., Linden, M., Werner, S., and Behrens, S. (2004b). Determinants of the quality of life (QoL) in patients with an implantable cardioverter/defibrillator (ICD). Qual. Life Res. 13, 411-416.

Goodman, M., and Hess, B. (1999). Could implantable cardioverter defibrillators provide a human model supporting the learned helplessness theory of depression? Gen. Hosp. Psychiatry 21, 382-385.

Habibovic, M., Van Den Broek, K. C., Alings, M., Van Der Voort, P. H., and Denollet, J. (2012). Posttraumatic stress 18 months following cardioverter defibrillator implantation: shocks, anxiety, and personality. Health Psychol. 31, 186-193. doi: 10.1037/a0024701

Heller, S. S., Ormont, M. A., Lidagoster, L., Sciacca, R. R., and Steinberg, S. (1998). Psychosocial outcome after ICD implantation: a current perspective. Pacing Clin. Electrophysiol. 21, 1207-1215.

Herbst, J. H., Goodman, M., Feldstein, S., and Reilly, J. M. (1999). Healthrelated quality-of-life assessment of patients with life-threatening ventricular arrhythmias. Pacing Clin. Electrophysiol. 22(6 Pt 1), 915-926.

Herrmann, C., Von Zur Muhen, F., Schaumann, A., Buss, U., Kemper, S., Wantzen, C., et al. (1997). Standardized assessment of psychological wellbeing and quality-of-life in patients with implanted defibrillators. Pacing Clin. Electrophysiol. 20, 95-103.

Irvine, J., Dorian, P., Baker, B., O’brien, B. J., Roberts, R., Gent, M., et al. (2002). Quality of life in the Canadian Implantable Defibrillator Study (CIDS). Am. Heart J. 144, 282-289. doi: 10.1067/mjh.2002.124049

Jacq, F., Foulldrin, G., Savoure, A., Anselme, F., Baguelin-Pinaud, A., Cribier, A., et al. (2009). A comparison of anxiety, depression and quality of life between device shock and nonshock groups in implantable cardioverter defibrillator recipients. Gen. Hosp. Psychiatry 31, 266-273. doi: 10.1016/j.genhosppsych.2009.01.003

Johansen, J. B., Pedersen, S. S., Spindler, H., Andersen, K., Nielsen, J. C., and Mortensen, P. T. (2008). Symptomatic heart failure is the most important 
clinical correlate of impaired quality of life, anxiety, and depression in implantable cardioverter-defibrillator patients: a single-centre, cross-sectional study in 610 patients. Europace 10, 545-551. doi: 10.1093/europace/eun073

Kamphuis, H. C., De Leeuw, J. R., Derksen, R., Hauer, R., and Winnubst, J. A. (2002). A 12-month quality of life assessment of cardiac arrest survivors treated with or without an implantable cardioverter defibrillator. Europace 4, 417-425. doi: 10.1053/eupc.2002.0258

Kamphuis, H. C., De Leeuw, J. R., Derksen, R., Hauer, R. N., and Winnubst, J. A. (2003). Implantable cardioverter defibrillator recipients: quality of life in recipients with and without ICD shock delivery: a prospective study. Europace 5, 381-389. doi: 10.1016/S1099-5129(03)00078-3

Kapa, S., Rotondi-Trevisan, D., Mariano, Z., Aves, T., Irvine, J., Dorian, P., et al. (2010). Psychopathology in patients with ICDs over time: results of a prospective study. Pacing Clin. Electrophysiol. 33, 198-208. doi: 10.1111/j.15408159.2009.02599.x

Keren, A., Sears, S. F., Nery, P., Shaw, J., Green, M. S., Lemery, R., et al. (2011). Psychological adjustment in ICD patients living with advisory fidelis leads. J. Cardiovasc. Electrophysiol. 22, 57-63. doi: 10.1111/j.1540-8167.2010.01867.x

Keren, R., Aarons, D., and Veltri, E. P. (1991). Anxiety and depression in patients with life-threatening ventricular arrhythmias: impact of the implantable cardioverter-defibrillator. Pacing Clin. Electrophysiol. 14, 181-187.

Kuck, K. H., Cappato, R., Siebels, J., and Ruppel, R. (2000). Randomized comparison of antiarrhythmic drug therapy with implantable defibrillators in patients resuscitated from cardiac arrest: the Cardiac Arrest Study Hamburg (CASH). Circulation 102, 748-754. doi: 10.1161/01.CIR.102.7.748

Ladwig, K. H., Baumert, J., Marten-Mittag, B., Kolb, C., Zrenner, B., and Schmitt, C. (2008). Posttraumatic stress symptoms and predicted mortality in patients with implantable cardioverter-defibrillators: results from the prospective living with an implanted cardioverter-defibrillator study. Arch. Gen. Psychiatry 65, 1324-1330. doi: 10.1001/archpsyc.65.11.1324

Leosdottir, M., Sigurdsson, E., Reimarsdottir, G., Gottskalksson, G., Torfason, B., Vigfusdottir, M., et al. (2006). Health-related quality of life of patients with implantable cardioverter defibrillators compared with that of pacemaker recipients. Europace 8, 168-174. doi: 10.1093/europace/euj052

Liberati, A., Altman, D. G., Tetzlaff, J., Mulrow, C., Gotzsche, P. C., Ioannidis, J. P., et al. (2009). The PRISMA statement for reporting systematic reviews and meta-analyses of studies that evaluate health care interventions: explanation and elaboration. Ann. Intern. Med. 151, W65-W94. doi: 10.7326/0003-4819-151-4200908180-00136

Luderitz, B., Jung, W., Deister, A., Marneros, A., and Manz, M. (1993). Patient acceptance of the implantable cardioverter defibrillator in ventricular tachyarrhythmias. Pacing Clin. Electrophysiol. 16, 1815-1821.

Luyster, F. S., Hughes, J. W., Waechter, D., and Josephson, R. (2006). Resource loss predicts depression and anxiety among patients treated with an implantable cardioverter defibrillator. Psychosom. Med. 68, 794-800. doi: 10.1097/01.psy. 0000227722.92307.35

Mark, D. B., Anstrom, K. J., Sun, J. L., Clapp-Channing, N. E., Tsiatis, A. A., Davidson-Ray, L., et al. (2008). Quality of life with defibrillator therapy or amiodarone in heart failure. N. Engl. J. Med. 359, 999-1008. doi: 10.1056/NEJMoa0706719

Mishkin, J. D., Saxonhouse, S. J., Woo, G. W., Burkart, T. A., Miles, W. M., Conti, J. B., et al. (2009). Appropriate evaluation and treatment of heart failure patients after implantable cardioverter-defibrillator discharge: time to go beyond the initial shock. J. Am. Coll. Cardiol. 54, 1993-2000. doi: 10.1016/j.jacc.2009. 07.039

Morris, P. L., Badger, J., Chmielewski, C., Berger, E., and Goldberg, R. J. (1991). Psychiatric morbidity following implantation of the automatic implantable cardioverter defibrillator. Psychosomatics 32, 58-64.

Moss, A. J., Zareba, W., Hall, W. J., Klein, H., Wilber, D. J., Cannom, D. S., et al. (2002). Prophylactic implantation of a defibrillator in patients with myocardial infarction and reduced ejection fraction. Multicenter Automatic Defibrillator Implantation Trial II Investigators. N. Engl. J. Med. 346, 877-883. doi: 10.1056/NEJMoa013474 NEJMoa013474 [pii]

Namerow, P. B., Firth, B. R., Heywood, G. M., Windle, J. R., and Parides, M. K. (1999). Quality-of-life six months after CABG surgery in patients randomized to ICD versus no ICD therapy: findings from the CABG Patch Trial. Pacing Clin. Electrophysiol. 22, 1305-1313.

Newman, D. M., Dorian, P., Paquette, M., Sulke, N., Gold, M. R., Schwartzman, D. S., et al. (2003). Effect of an implantable cardioverter defibrillator with atrial detection and shock therapies on patient-perceived, health-related quality of life. Am. Heart J. 145, 841-846. doi: 10.1016/S0002-8703(02)94817-9

Noyes, K., Corona, E., Veazie, P., Dick, A. W., Zhao, H., and Moss, A. J. (2009). Examination of the effect of implantable cardioverter-defibrillators on health-related quality of life: based on results from the Multicenter Automatic Defibrillator Trial-II. Am. J. Cardiovasc. Drugs 9, 393-400. doi: 10.2165/11317980-000000000-00000

Passman, R., Subacius, H., Ruo, B., Schaechter, A., Howard, A., Sears, S. F., et al. (2007). Implantable cardioverter defibrillators and quality of life: results from the defibrillators in nonischemic cardiomyopathy treatment evaluation study. Arch. Intern. Med. 167, 2226-2232. doi: 10.1001/archinte.167.20.2226

Pauli, P., Wiedemann, G., Dengler, W., Blaumann-Benninghoff, G., and Kuhlkamp, V. (1999). Anxiety in patients with an automatic implantable cardioverter defibrillator: what differentiates them from panic patients? Psychosom. Med. 61, 69-76.

Pedersen, S. S., den Broek, K. C., Theuns, D. A., Erdman, R. A., Alings, M., Meijer, A., et al. (2011). Risk of chronic anxiety in implantable defibrillator patients: a multi-center study. Int. J. Cardiol. 147, 420-423. doi: 10.1016/j.ijcard.2009. 09.549

Pedersen, S. S., Spindler, H., Johansen, J. B., and Mortensen, P. T. (2009). Clustering of poor device acceptance and Type D personality is associated with increased distress in Danish cardioverter-defibrillator patients. Pacing Clin. Electrophysiol. 32, 29-36. doi: 10.1111/j.1540-8159.2009.02173.x

Pedersen, S. S., Spindler, H., Johansen, J. B., Mortensen, P. T., and Sears, S. F. (2008a). Correlates of patient acceptance of the cardioverter defibrillator: crossvalidation of the Florida patient acceptance survey in Danish patients. Pacing Clin. Electrophysiol. 31, 1168-1177. doi: 10.1111/j.1540-8159.2008.01158.x

Pedersen, S. S., Theuns, D. A., Erdman, R. A., and Jordaens, L. (2008b). Clustering of device-related concerns and type D personality predicts increased distress in ICD patients independent of shocks. Pacing Clin. Electrophysiol. 31, 20-27. doi: 10.1111/j.1540-8159.2007.00921.x

Pedersen, S. S., Theuns, D. A., Jordaens, L., and Kupper, N. (2010a). Course of anxiety and device-related concerns in implantable cardioverter defibrillator patients the first year post implantation. Europace 12, 1119-1126. doi: 10.1093/europace/euq154

Pedersen, S. S., Theuns, D. A., Muskens-Heemskerk, A., Erdman, R. A., and Jordaens, L. (2007). Type-D personality but not implantable cardioverter-defibrillator indication is associated with mpaired healthrelated quality of life 3 months post-implantation. Europace 9, 675-680. doi: 10.1093/europace/eum041

Pedersen, S. S., and Van Den Broek, K. C. (2008). Implantable cardioverterdefibrillator shocks and their adverse impact on patient-centered outcomes: fact or fiction? J. Am. Coll. Cardiol. 52, 1037-1038. doi: 10.1016/j.jacc.2008.04.066

Pedersen, S. S., Van Den Broek, K. C., Van Den Berg, M., and Theuns, D. A. (2010b). Shock as a determinant of poor patient-centered outcomes in implantable cardioverter defibrillator patients: is there more to it than meets the eye? Pacing Clin. Electrophysiol. 33, 1430-1436. doi: 10.1111/j.1540-8159.2010.02845.x

Pedersen, S. S., Van Domburg, R. T., Theuns, D. A., Jordaens, L., and Erdman, R. A. (2004). Type D personality is associated with increased anxiety and depressive symptoms in patients with an implantable cardioverter defibrillator and their partners. Psychosom Med. 66, 714-719. doi 10.1097/01.psy.0000132874.52202.21 66/5/714 [pii]

Pedersen, S. S., Van Domburg, R. T., Theuns, D. A., Jordaens, L., and Erdman, R. A. (2005). Concerns about the implantable cardioverter defibrillator: a determinant of anxiety and depressive symptoms independent of experienced shocks. Am. Heart J. 149, 664-669. doi: 10.1016/j.ahj.2004.06.031

Piotrowicz, K., Noyes, K., Lyness, J. M., Mcnitt, S., Andrews, M. L., Dick, A., et al. (2007). Physical functioning and mental well-being in association with health outcome in patients enrolled in the multicenter automatic defibrillator implantation Trial II. Eur. Heart J. 28, 601-607. doi: 10.1093/eurheartj/ ehl485

Redhead, A. P., Turkington, D., Rao, S., Tynan, M. M., and Bourke, J. P. (2010). Psychopathology in postinfarction patients implanted with cardioverterdefibrillators for secondary prevention. A cross-sectional, case-controlled study. J. Psychosom. Res. 69, 555-563. doi: 10.1016/j.jpsychores.2010.06.002

Schron, E. B., Exner, D. V., Yao, Q., Jenkins, L. S., Steinberg, J. S., Cook, J. R., et al. (2002). Quality of life in the antiarrhythmics versus implantable defibrillators trial: impact of therapy and influence of adverse symptoms and defibrillator shocks. Circulation 105, 589-594. doi: 10.1161/hc0502.103330 
Sears, S. F., and Kirian, K. (2010). Shock and patient-centered outcomes research: is an ICD shock still a critical event? Pacing Clin. Electrophysiol. 33, 1437-1441. doi: 10.1111/j.1540-8159.2010.02872.x

Sears, S. F., Lewis, T. S., Kuhl, E. A., and Conti, J. B. (2005). Predictors of quality of life in patients with implantable cardioverter defibrillators. Psychosomatics 46, 451-457. doi: 10.1176/appi.psy.46.5.451

Sears, S. F., Sowell, L. V., Kuhl, E. A., Handberg, E. M., Kron, J., Aranda, J. M. Jr., et al. (2006). Quality of death: implantable cardioverter defibrillators and proactive care. Pacing Clin. Electrophysiol. 29, 637-642. doi: 10.1111/j.15408159.2006.00412.x

Sears, S. F. Jr., Todaro, J. F., Lewis, T. S., Sotile, W., and Conti, J. B. (1999). Examining the psychosocial impact of implantable cardioverter defibrillators: a literature review. Clin. Cardiol. 22, 481-489.

Sossong, A. (2007). Living with an implantable cardioverter defibrillator: patient outcomes and the nurse's role. J. Cardiovasc. Nurs. 22, 99-104.

Spindler, H., Johansen, J. B., Andersen, K., Mortensen, P., and Pedersen, S. S. (2009). Gender differences in anxiety and concerns about the cardioverter defibrillator. Pacing Clin. Electrophysiol. 32, 614-621. doi: 10.1111/j.15408159.2009.02334.x

Strickberger, S. A., Hummel, J. D., Bartlett, T. G., Frumin, H. I., Schuger, C. D., Beau, S. L., et al. (2003). Amiodarone versus implantable cardioverterdefibrillator:randomized trial in patients with nonischemic dilated cardiomyopathy and asymptomatic nonsustained ventricular tachycardiaAMIOVIRT. J. Am. Coll. Cardiol. 41, 1707-1712. doi: 10.1016/S0735-1097(03) 00297-3

Suzuki, T., Shiga, T., Kuwahara, K., Kobayashi, S., Suzuki, S., Nishimura, K., et al. (2010). Prevalence and persistence of depression in patients with implantable cardioverter defibrillator: a 2-year longitudinal study. Pacing Clin. Electrophysiol. 33, 1455-1461. doi: 10.1111/j.1540-8159.2010.02887.x

Thomas, S. A., Friedmann, E., Gottlieb, S. S., Liu, F., Morton, P. G., Chapa, D. W., et al. (2009). Changes in psychosocial distress in outpatients with heart failure with implantable cardioverter defibrillators. Heart and Lung: the J. Critical Care 38, 109-120.

Van Den Broek, K. C., Nyklicek, I., and Denollet, J. (2009). Anxiety predicts poor perceived health in patients with an implantable defibrillator. Psychosomatics 50, 483-492. doi: 10.1176/appi.psy.50.5.483

Van Den Broek, K. C., Nyklicek, I., Van Der Voort, P. H., Alings, M., and Denollet, J. (2008). Shocks, personality, and anxiety in patients with an implantable defibrillator. Pacing Clin. Electrophysiol. 31, 850-857. doi: 10.1111/j.15408159.2008.01099.x

Versteeg, H., Theuns, D. A., Erdman, R. A., Jordaens, L., and Pedersen, S. S. (2010). Posttraumatic stress in implantable cardioverter defibrillator patients: the role of pre-implantation distress and shocks. Int. J. Cardiol. 146, 438-439. doi: 10.1016/j.ijcard.2010.10.108

Von Känel, R., Baumert, J., Kolb, C., Cho, E.-Y. N., and Ladwig, K.-H. (2011). Chronic posttraumatic stress and its predictors in patients living with an implantable cardioverter defibrillator. J. Affect. Disord. 131, 344-352. doi: 10.1016/j.jad.2010.12.002

Wallace, R. L., Sears, S. F. Jr., Lewis, T. S., Griffis, J. T., Curtis, A., and Conti, J. B. (2002). Predictors of quality of life in long-term recipients of implantable cardioverter defibrillators. J. Cardiopulm. Rehabil. 22, 278-281.

Wathen, M. S., Degroot, P. J., Sweeney, M. O., Stark, A. J., Otterness, M. F., Adkisson, W. O., et al. (2004). Prospective randomized multicenter trial of empirical antitachycardia pacing versus shocks for spontaneous rapid ventricular tachycardia in patients with implantable cardioverter-defibrillators: pacing fast ventricular tachycardia reduces shock therapies (PainFREE Rx II) trial results. Circulation 110, 2591-2596. doi: 10.1161/01.CIR.0000145610. 64014.E4

Conflict of Interest Statement: The authors declare that the research was conducted in the absence of any commercial or financial relationships that could be construed as a potential conflict of interest.

Received: 05 September 2014; paper pending published: 05 November 2014; accepted: 08 January 2015; published online: 04 February 2015.

Citation: Manzoni GM, Castelnuovo G, Compare A, Pagnini F, Essebag V and Proietti $R$ (2015) Psychological effects of implantable cardioverter defibrillator shocks. A review of study methods. Front. Psychol. 6:39. doi: 10.3389/fpsyg.2015.00039

This article was submitted to Psychology for Clinical Settings, a section of the journal Frontiers in Psychology.

Copyright (C) 2015 Manzoni, Castelnuovo, Compare, Pagnini, Essebag and Proietti. This is an open-access article distributed under the terms of the Creative Commons Attribution License (CC BY). The use, distribution or reproduction in other forums is permitted, provided the original author (s) or licensor are credited and that the original publication in this journal is cited, in accordance with accepted academic practice. No use, distribution or reproduction is permitted which does not comply with these terms. 